\title{
Optimal Taxation of Capital in the Presence of Declining Labor Share
}

Orhan Erem Atesagaoglu Hakki Yazici

Discussion Paper 21/739

10 March 2021

School of Economics

University of Bristol

Priory Road Complex

Bristol

BS8 1TU

United Kingdom

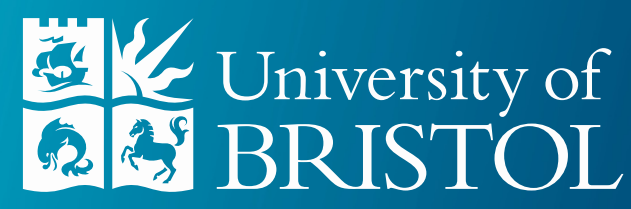

School of Economics 


\title{
Optimal Taxation of Capital in the Presence of Declining Labor Share*
}

\author{
Orhan Erem Atesagaoglu ${ }^{\dagger}$ and Hakki Yazici ${ }^{\ddagger}$
}

March 10, 2021

Numerous recent studies have documented that the labor's share in national income, which has been quite stable until the early 1980's, has been declining at a considerable rate since then. In this paper, we analyze the implications of this decline on the optimal capital and labor income taxation from the perspective of a government that needs to finance spending. Our main qualitative finding is that the optimal tax implications of the decline in the labor share depend on the mechanism responsible for it. In particular, if the labor share is declining because of rising market power or other mechanisms that raise the share of profits in national income, then this decline should optimally be accompanied with a rise in capital income taxes. If, on the other hand, the labor share is declining because of a rise in capital share, then it has no bearing on optimal capital income taxation. The quantitative significance of the decline in labor share for optimal capital taxes depends on the institutional details regarding the taxation of profits: in the baseline scenario, the optimal tax rate on capital income for the U.S. economy starts around zero in early 1980's and rises to about $25 \%$ by 2021 in response to the decline in labor share during the same period.

JEL classification: E60, E61, E62

Keywords: Capital income tax; labor share; profit share

${ }^{*}$ We would like to thank Arpad Abraham, Melanie Luhrmann, seminar audiences at Bogazici University, University of Bristol, University of Royal Holloway, and participants at European Economic Association 2020 Meetings for their comments and suggestions.

$\dagger$ Istanbul Bilgi University. E-mail: erem.atesagaoglu@bilgi.edu.tr

$\ddagger$ University of Bristol. E-mail: hakki.yazici@bristol.ac.uk 


\section{Introduction}

Governments use income taxes and debt to finance their spending. A central question in macroeconomics is: How should governments allocate the tax burden between two main tax bases, capital and labor income, over time? An influential literature - dating back to the original contribution of Ramsey (1928) - provides a key insight regarding this question: it is optimal to set the capital tax rate to zero. Judd (1985) and Chamley (1986) were the first ones to show that capital taxes should be zero in the long run in the neoclassical growth model. ${ }^{1}$ If one is willing to assume that preferences belong to a class that is standard in the macroeconomics literature, then the long-run result holds in the short run as well: except for a few initial periods, it is optimal to set taxes on capital income to zero and put all the burden of taxation on the labor income tax base.

In this paper, we analyze optimal capital and labor income taxation in an economy where the labor tax base is shrinking. This is a very relevant issue from the perspective of practical policymaking since there is a relatively broad consensus among economists that the labor's share in national income (labor share hereafter) has been declining in many developed economies. $^{2}$ Figure $_{1}$ below depicts the labor share for the US economy for the post war era. The labor share is stable until the early 1980's and has been falling at a considerable rate since then. This trend implies that a government that follows the suggestions of the Ramsey tax theory, by setting capital income taxes to zero or at least by keeping them low relative to labor income taxes, would experience a decline in overall tax revenue. Such a government would have to reform its tax system in order to make up for this decline. In an interview with Quartz in 2017, Bill Gates famously addressed this issue by stating that "Robots who

\footnotetext{
${ }^{1}$ Straub and Werning (2020) provide a set of conditions under which the optimality of zero taxes on capital in the long run does not hold. Chari, Nicolini, and Teles (2020) show that with a richer set of tax instruments and under the assumption that initial confiscation of wealth is restricted, one recovers the longrun optimality of zero capital taxes. See Chari and Kehoe (1999) for a thorough discussion of the earlier contributions to the Ramsey tax literature.

${ }^{2}$ See Elsby, Hobijn, and Sahin (2013), Karabarbounis and Neiman (2014), Autor, Dorn, Katz, Patterson, and Reenen (2017), Barkai (2019), De Loecker, Eeckhout, and Unger (2019), Acemoglu and Restrepo (2019), and Farhi and Gourio (2018).
} 
take human jobs should pay taxes!" Since robots are part of the capital stock, his suggestion could be interpreted as raising the capital tax rate. Interestingly, the academic literature has remained silent on this important, policy-relevant question. In this paper, we take a first step in this direction and investigate the optimal way of reforming the tax system in the presence of a decline in the labor share using a standard macroeconomic model.

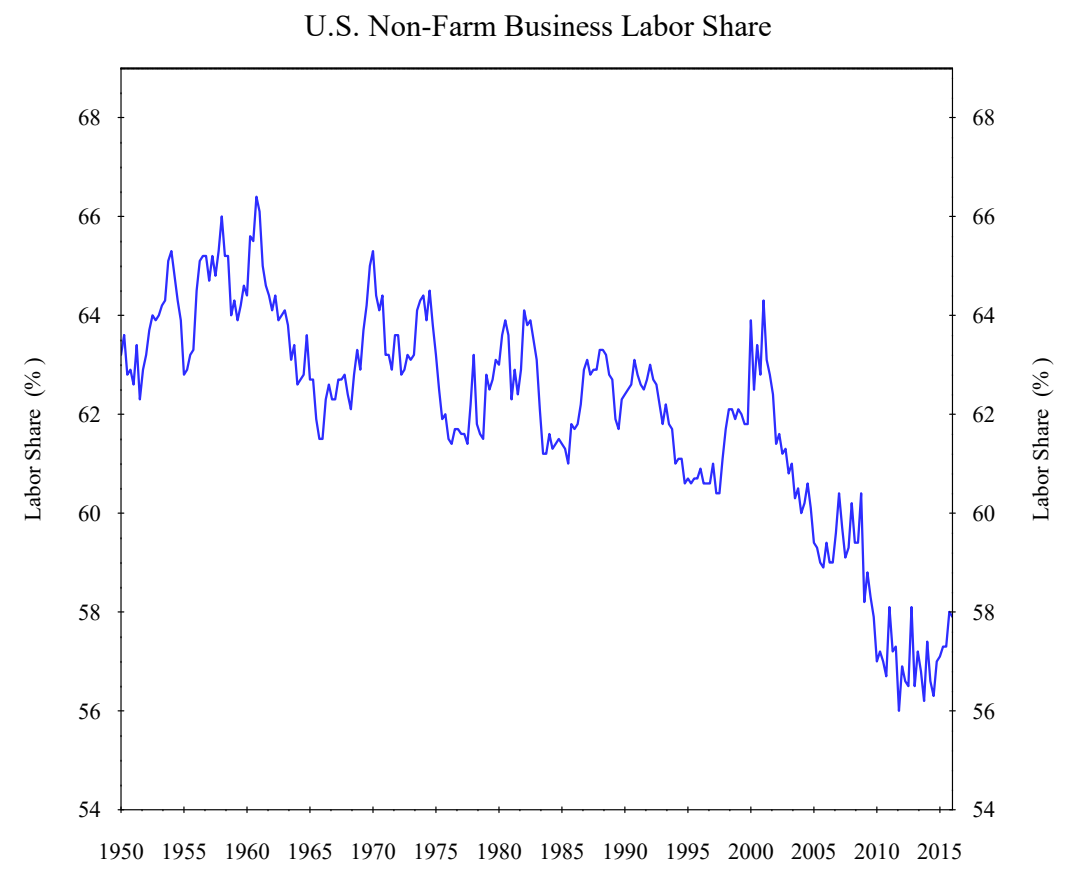

Figure 1: U.S. Non-Farm Business Labor Share

To do so, we set up a representative agent neoclassical growth model in which there is a government that needs to finance an exogenous stream of expenditures using linear taxes on capital and labor income. We focus on a representative agent framework intentionally in order to avoid issues of inequality and redistribution. We allow for the possibility that firms may earn pure economic profits by modelling monopolistic competition in the product market. There is diverse opinion in the literature on the mechanisms that are responsible for the decline in labor share. Because we do not want to take a stance on which mechanisms are more important before we derive our qualitative results, our neoclassical growth model incorporates virtually all of them. 
Observe that the following equality holds in any economy in any given year:

$$
Y=I_{L}+I_{K}+I_{\Pi}
$$

where $Y$ is national income, $I_{L}$ is the aggregate labor income received by workers, $I_{K}$ is the aggregate capital income received by those who own the capital stock, and $I_{\Pi}$ is the aggregate (pure) profit income received by firm owners. The profit income is defined as the earnings of firms in excess of all production costs. The equality in (1) simply tells us that the national income is shared between labor income, capital income, and profit income. Therefore, if there is a decline in labor share, this must be happening due to a rise in capital share or a rise in profit share, or both. We categorize the theories of the decline in labor share proposed in the literature into two groups depending on whether they involve a rise in capital or profit share of income. Rise in automation, capital augmenting technical change, decline in capital prices and offshoring of labor-intensive production are all theories of rise in capital share whereas rising market power and rising returns to production inputs that are in fixed supply are theories of increasing profit share.

Our main qualitative finding is that the nature of the optimal tax reform for an economy that experiences a decline in labor share depends on whether this decline is accompanied by a rise in capital or profit share. If labor share is declining because production is becoming more capital intensive, say due to a rise in automation or cheapening of capital, then it is optimal to increase labor income taxes to make up for the loss in tax revenue. If, on the other hand, the decline in labor share coincides with a rise in profit share, say due to declining competition in product markets, then it is optimal to increase the tax rate on capital income.

Intuitively, whenever an economy is generating pure profits, it is optimal for the government to tax them away fully since taxing pure profits is non-distortionary. If taxing profit income at $100 \%$ is not an option for the government, an assumption maintained in the current paper, then it is optimal to tax factors that contribute to profit creation as this provides 
an indirect way of taxing profits. Obviously, capital is one such factor as it contributes to production, and hence, profit generation. Motivated by the observation that it is in general quite hard for governments to distinguish between capital and profit income, in our baseline optimal tax analysis we assume that government chooses a uniform tax rate that applies to both capital and profit income. This introduces another reason to tax capital since, under this assumption, a tax on capital income acts directly as a tax on profit income as well.

In line with the discussion above, the optimal capital tax formula consists of two components which reflect the indirect and the direct profit tax revenue benefits of capital taxation. The formula reveals that the optimal tax rate on capital income is proportional to the share of profits in national income. Additionally, we derive an alternative expression for the optimal capital tax formula, and use it to deliver a simple expression for a lower bound on the optimal capital tax rate which depends on empirically estimable quantities. The lower bound increases with the profit share and the relative social value of public funds, while it decreases with the elasticity of national income with respect to the retention rate (one minus the tax rate) on capital income.

When profits are generated due to presence of market power as in our model, firms display inefficiently low investment and labor demand, which implies there is also a motive to subsidize investment and employment. In our baseline implementation, we assume that these inefficiencies are dealt with at the firm level, where they originate, through product market interventions. ${ }^{3}$ As an alternative implementation, we also consider the case in which the government does not have access to product market policies, and show that, in this case, in addition to the direct and indirect tax motives explained above, an additional Pigouvian subsidy term appears in the optimal capital tax formula.

On the quantitative side, we calibrate our model to the decline in labor share observed

\footnotetext{
${ }^{3}$ This implementation is in line with a growing literature that studies how to design product market policies in correcting inefficiencies stemming from market power. See, among others, Edmond, Midrigan, and Xu (2018), Atkeson and Burstein (2019), and Boar and Midrigan (2020). Our paper differs from these papers in the sense that while our focus is on the optimal financing of government spending using income taxation they focus on correcting inefficiencies stemming from product market distortions.
} 
in the US economy. Specifically, we calibrate the steady state of our model economy to early 1980's U.S. economy in line with the empirical observations that the labor share was stable at two thirds and the profit share was around zero. We then calibrate the evolution of the model economy to match the empirical evolution of income shares in the US since the early 1980's. Following Barkai (2019) and De Loecker, Eeckhout, and Unger (2019), we target a $15 \%$ increase in profit share during this period.

We first consider a hypothetical case in which the government carries out the optimal tax reform in early 1980's foreseeing the upcoming trends in income shares. The optimal tax rate on capital income starts low and goes up to about $25 \%$ by 2021, and stabilizes at around $27 \%$ in the long run whereas the optimal tax on labor income is virtually flat at around $32 \%$. The optimal capital tax rate is low early on because the profit share is low in the 1980's, and the only motive to tax capital in the current model is to tax profit income. After that, the optimal capital tax rate follows closely the pattern of rising profit share. We then consider an optimal tax reform in 2021 . We find that the optimal capital tax rate starts from about $26 \%$ and rises to $28 \%$ in the long run. The optimal labor income tax rate is again smooth, now around the somewhat higher level of $34 \%$. The optimal tax rates are higher in the 2021 reform because public debt is higher at the time of the 2021 reform, which may be seen a result of decades of inefficient tax policy since early 1980's. The optimal tax rate on capital income is lower but still significantly positive in the case in which product market interventions are not possible: in the 1980's reform it rises to about $8 \%$ by 2021 , the level at which it settles down in the long run, and in the 2021 reform it starts around $10 \%$ the level at which it stays in the long run.

We also consider alternative institutional arrangements that may matter for optimal taxation. First, we investigate optimal taxation in a world in which government cannot correct product market distortions at all, and show that the optimal capital tax formula is virtually the same as in the baseline analysis in which distortions are corrected via product market subsidies. Second, we consider an environment in which the government is allowed 
to tax capital and profit income at different rates, but there is an (exogenous) upper bound on the profit tax rate. We find that the optimal capital tax formula in this case only features the indirect profit tax revenue component. In both of these alternative scenarios, our quantitative analyses show that the optimal taxes on capital income are qualitatively in line with the quantitative findings in our baseline scenario: optimal capital taxes increase as labor share declines, and are quantitatively significantly positive by 2021 and remain so in the long run.

It is important to stress that in this model the only reason for taxing capital is financing government spending. In reality, there may be other reasons for taxing capital such as redistribution. In this regard, the optimal capital tax rates we compute here should be seen as informative about how strong our mechanism is for capital taxation and not as a prescription for actual capital tax rates.

Related Literature. Our paper is related to several strands of literature, though, to the best of our knowledge, no other paper analyzes how to reform the tax system in response to declining labor share. First, in our environment, the optimality of increasing capital taxes in response to declining labor share comes from the rise in profit share. In this regard, an influential backdrop to our paper is Dasgupta and Stiglitz (1971) who show that, when there are pure profits in an economy due to decreasing returns to scale in production and profit tax rate is exogenously restricted to be less than $100 \%$, the productive efficiency result of Diamond and Mirrlees (1971) does not hold any more which implies that it is then optimal to tax intermediate inputs that contribute to profit creation since taxing these inputs provide an indirect tax on profits. Jones, Manuelli, and Rossi (1997) show that this logic implies a positive tax on capital in the long run in the context of the neoclassical growth model in which profits arise in equilibrium due to inelastic labor supply. Also related are a set of papers that investigate optimal taxation in the presence of product market power. Judd (2002) shows that, when there are profits in equilibrium due to monopolistic competition in the product 
market and the profit tax rate is exogenously restricted to be below 100\%, the overall optimal long-run capital wedge is negative, asking for capital subsidies. Guo and Lansing (1999) and Coto-Martínez, Garriga, and Sánchez-Losada (2007) question the generality of Judd (2002)'s long-run capital subsidy result by considering restricted government policies and different economic environments. These papers study the sign of the optimal long-run capital tax rate. Our paper differs from this literature as it analyzes the optimal reform of the tax system in response to declining labor share. We contribute by both providing qualitative lessons as to when capital taxes become an important part of such a reform and by providing a quantitative analysis of how strong the capital tax response should be. Our analysis also incorporates various institutional arrangements that are currently debated in policy circles, such as the use of product market policies, to the taxation of capital and labor income.

Second, there is a burgeoning literature that makes a case for taxation of robots and automation technologies. Following the skill premium literature, Slavik and Yazici (2014) assume a machine-skill complementarity. This implies that machines raise the marginal product of the skilled relative to the unskilled, and this increases inequality. It is, thus, desirable to deter the accumulation of machines from the perspective of a redistributive government. Costinot and Werning (2018) argue for a similar rationale for taxing robots and trade in a static model with a more general production structure. ${ }^{4}$ In all these papers taxing robots is socially desirable because it is redistributive while we argue that taxing robots (or capital in general) provides a more efficient way of financing government's budget when capital accumulation contributes to creation of pure economic profits. ${ }^{5}$ More closely related is Acemoglu, Manera, and Restrepo (2020) who investigate the optimal taxation of capital and labor in a task-based framework of automation. Like our paper, they abstract from redistributive concerns by assuming a representative agent. While we allow for different

\footnotetext{
${ }^{4}$ See also Thuemmel (2018) and Guerreiro, Rebelo, and Teles (2019) for similar arguments for taxation of robots.

${ }^{5}$ There is also a growing literature on the optimal redistributive taxation of capital using quantitative models with rich heterogeneity and uninsured income risk. See, among others, Domeij and Heathcote (2004) and Conesa, Kitao, and Krueger (2009).
} 
competing mechanisms behind the decline of labor share, they focus on automation, and show that the optimal capital tax rate is positive. ${ }^{6}$ Their quantitative analysis shows that optimal capital tax rate is larger than the effective actual tax rate on capital in the United States, implying that the US tax system is biased in favor of capital.

Finally, our modelling of the rise in market power as the main driving force behind the decline in labor share builds on the seminal works of Barkai (2019), De Loecker, Eeckhout, and Unger (2019) and Philippon (2019). Caballero, Farhi, and Gourinchas (2017), Eggertsson, Robbins, and Wold (2018), and Farhi and Gourio (2018) argue that increasing market power as a driver of declining labor share has an additional merit that it helps explain other key macroeconomic trends in the US economy around the same time period. Our calibration echoes these arguments: we find that the rise in market power also explains the bulk of the rise in the divergence of the returns to productive capital and the risk-free rate that is observed in the US economy during this period. More generally, the current paper complements the positive findings of this literature by taking a normative perspective and analyzing optimal taxation under key recent macroeconomics trends.

The organization of the article is as follows. Section 2 presents the model. Section 3 presents the theoretical analysis of optimal taxation for the case without product market policies. Section 4 lays down the theoretical analysis of optimal taxation in the presence of product market interventions. Section 5 presents the calibration and quantitative results. Section 6 focuses on the alternative case in which the government cannot correct monopolistic distortions. Section 7 focuses on another alternative case in which the profit taxes are exogenous. Finally, Section 8 concludes.

\footnotetext{
${ }^{6}$ It is optimal to tax capital in Acemoglu, Manera, and Restrepo (2020) because the authors assume that the government should balance its budget period by period. If one instead allows for a, perhaps more standard, intertemporal government budget, then one recovers the optimality of zero capital taxes in the long run in their environment. This is in line with our result that capital-intensive theories of the decline in labor share such as automation do not justify taxing capital income.
} 


\section{Model}

Consider a neoclassical growth model in which there is a representative consumer who lives infinitely many periods. We introduce profits into our environment in the simplest possible manner: Dixit-Stiglitz monopolistic competition. This is the key departure of our model from the neoclassical growth model. ${ }^{7}$ Specifically, there are also firms that produce and sell intermediate and final goods. All firms are owned by the representative consumer. Finally, there is a benevolent government that needs to finance a given stream of public spending.

Final Good Producers. Firms that produce the final good are perfectly competitive and operate a constant elasticity of substitution (CES) production function that combines measure one of intermediate goods $y_{i, t}$. Taking prices of intermediate goods, $\xi_{i, t}$, as given, the problem of the representative final good firm is:

$$
\begin{gathered}
\max _{y_{i, t}} y_{t}-\int_{0}^{1} \xi_{i, t} y_{i, t} d i \\
\text { s.t. } \\
y_{t}=\left(\int_{0}^{1} y_{i, t}^{\frac{\varepsilon_{t}-1}{\varepsilon_{t}}} d i\right)^{\frac{\varepsilon_{t}}{\varepsilon_{t}-1}} .
\end{gathered}
$$

The first-order optimality condition of this problem with respect to $y_{i, t}$ gives the demand as a function of price for each intermediate good:

$$
y_{i, t}=y_{t} \xi_{i, t}^{-\varepsilon_{t}}
$$

Intermediate Good Producers. Each intermediate good producer is a monopolistic competitor. Producer of intermediate good $y_{i, t}$ uses a CES technology, $F_{t}$, to combine capital

\footnotetext{
${ }^{7}$ Although our exposition uses monopolistic competition to generate pure profits, the results of our model are more general. As we shall see in Section 3, independent of the microfoundation behind it, as long as labor share declines due to rising profit share, it is optimal to have rising capital income taxes.
} 
and labor to produce the intermediate good. This firm solves:

$$
\begin{gathered}
\pi_{i, t}=\max _{\xi_{i, t}, y_{i, t}, k_{i, t}, l_{i, t}} \xi_{i, t} y_{i, t}-r_{t} k_{i, t}-w_{t} l_{i, t} \\
\text { s.t. } \\
y_{i, t}=F_{t}\left(k_{i, t}, l_{i, t}\right)
\end{gathered}
$$

where $r_{t}$ and $w_{t}$ represent the real rental rate of capital and real wage rate, respectively.

The problem of the intermediate good producer can be solved in two steps. In the first step, for a given marginal cost of producing the intermediate good, $m_{i, t}$, the firm chooses its price to maximize profits:

$$
\max _{\xi_{i, t}} \xi_{i, t} y_{i, t}-m_{i, t} y_{i, t} \quad \text { s.t. } \quad(2)
$$

The solution to this problem implies a constant markup over marginal cost

$$
\xi_{i, t}=m_{i, t} \frac{\varepsilon_{t}}{\left(\varepsilon_{t}-1\right)}
$$

We focus on the symmetric equilibrium of the model in which all intermediate goods firms make identical choices of inputs and prices. This implies $y_{i, t}=y_{t}$ and $\xi_{i, t}=1$ for all $i \in[0,1]$. We, therefore, have the optimal marginal cost of producing one more intermediate good equals $m_{i, t}=m_{t}=1-\frac{1}{\varepsilon_{t}}$ for all firms.

In the second step, each firm chooses capital and labor to minimize the cost of producing the intermediate good. The firms also make same input choices in the symmetric equilibrium, so we have $k_{i, t}=k_{t}$ and $l_{i, t}=l_{t}$. The marginal cost of producing one more unit using capital or labor at the optimum equals

$$
\frac{r_{t}}{F_{k, t}}=\frac{w_{t}}{F_{l, t}}=1-\frac{1}{\varepsilon_{t}}
$$


where $F_{k, t}$ is short-hand notation for $\frac{\partial F_{t}\left(k_{l}, l_{t}\right)}{\partial k_{t}}$ and $F_{l, t}$ is defined analogously. Therefore, the rental rate and the wage rate are given by

$$
\begin{aligned}
& r_{t}=\left(1-\frac{1}{\varepsilon_{t}}\right) F_{k, t}, \\
& w_{t}=\left(1-\frac{1}{\varepsilon_{t}}\right) F_{l, t} .
\end{aligned}
$$

In this economy, as long as $\varepsilon_{t}$ is finite, the intermediate goods producers possess market power. This allows them to keep their sale prices high by producing at below the socially efficient level, which gives rise to inefficiently low demand for investment and labor. This is the reason why the rental rates of capital and labor are below the corresponding marginal products.

In our baseline implementation laid out later on in Section 4, the government corrects these inefficiencies by encouraging investment and employment at the level of intermediate goods producers via sales subsidies. We do not introduce these subsidies in the current section because, for expositional purposes, we find it more convenient to first display the implementation without product market subsidies (Section 3).

Income shares. Notice that since intermediate goods are used up in production, total income is given by the production of the final goods firm, $y_{t}$. Plugging (6) into (5) in the symmetric equilibrium implies that the total profit income generated by intermediate goods producing firms equals $\pi_{t}=\frac{1}{\varepsilon_{t}} y_{t}$. Thus, the share of profit income in total income in period $t$, denoted by $S_{\pi, t}$, equals

$$
S_{\pi, t} \equiv \frac{\pi_{t}}{y_{t}}=\frac{1}{\varepsilon_{t}}
$$


Next, using the rental rates given by $(7)$ - (8) to compute the income shares of capital and labor renders:

$$
\begin{aligned}
S_{k, t} & \equiv \frac{r_{t} k_{t}}{y_{t}}=\left(1-\frac{1}{\varepsilon_{t}}\right) \frac{F_{k, t} k_{t}}{y_{t}} \\
S_{l, t} & \equiv \frac{w_{t} l_{t}}{y_{t}}=\left(1-\frac{1}{\varepsilon_{t}}\right) \frac{F_{l, t} l_{t}}{y_{t}}
\end{aligned}
$$

Representative consumer. There is a unit measure of identical consumers who live forever. Each consumer is born in period one with $k_{1}>0$ units of physical capital and $b_{1}$ units of government debt. Taking prices as given, consumers decide on their consumption, labor, and saving allocations every period. Furthermore, they decide on how to allocate their saving between buying physical capita, government bonds, and private claims. The period utility of an individual who consumes $c$ units of consumption and supplies $l$ units of labor equals $u(c, l)$. The utility function satisfies standard assumptions, $u_{c},-u_{c c},-u_{l},-u_{l l}>0$, where $u_{c}$ and $u_{c c}$ are short-hand notation for $\frac{\partial u(c, l)}{\partial c}$ and $\frac{\partial^{2} u(c, l)}{\partial c \partial l}$, respectively, and $u_{l}$ and $u_{l l}$ are defined similarly. We also assume that utility is separable between consumption and labor, that is $u_{c l}=0$. The separability assumption is not important for the main results of this paper, and is adopted merely to make the derivations of the optimal tax formulas simpler. People discount future with a factor $\beta \in(0,1)$. Taking prices $\left\{p_{t}, r_{t}, w_{t}\right\}_{t=1}^{\infty}$, taxes $\left\{\tau_{k, t}, \tau_{l, t}, \tau_{\pi, t}\right\}_{t=1}^{\infty}$, and $k_{1}>0$ and $b_{1}$ as given, an individual chooses an allocation $(c, k, l) \equiv\left\{c_{t}, k_{t+1}, l_{t}\right\}_{t=1}^{\infty}$ to solve the following problem:

$$
\begin{gathered}
\max _{c, k, l} \sum_{t=1}^{\infty} \beta^{t-1} u\left(c_{t}, l_{t}\right) \\
\text { s.t. } \\
\sum_{t=1}^{\infty} p_{t}\left(c_{t}+q_{t} k_{t+1}\right) \leq \sum_{t=1}^{\infty} p_{t}\left(w_{t} l_{t}\left(1-\tau_{l, t}\right)+\bar{r}_{t} k_{t}+\pi_{t}\left(1-\tau_{\pi, t}\right)\right)+p_{1} b_{1},
\end{gathered}
$$

where $p_{t}$ is the period $t$ price of the consumption good, $q_{t}$ is the relative price of investment good in terms of the consumption good in period $t$, and $\bar{r}_{t}=q_{t}+\left(r_{t}-q_{t} \delta\right)\left(1-\tau_{k, t}\right)$ is 
the after-tax gross rate of return to capital. Looking at the right-hand side of the budget constraint above, we notice that the consumer has three sources of income: labor, capital and profit, each taxed at linear rates. Following the convention in actual tax systems, we allow for capital depreciation to be deducted from capital income tax base.

It is straightforward to derive the following first-order optimality conditions of the consumer's problem:

$$
\begin{aligned}
\frac{\beta u_{c, t+1}}{u_{c, t}} & =\frac{p_{t+1}}{p_{t}}, \\
p_{t} q_{t} & =p_{t+1} \bar{r}_{t+1}, \\
\frac{u_{l, t}}{u_{c, t}} & =-w_{t}\left(1-\tau_{l, t}\right) .
\end{aligned}
$$

When we combine the first-order optimality conditions of the consumer, (12) and (13), with the equilibrium rental rate of capital given by (7), we see that in equilibrium:

$$
u_{c, t-1} q_{t-1}=\beta u_{c, t}\left[q_{t}+\left(\left(1-\frac{1}{\varepsilon_{t}}\right) F_{k, t}-\delta q_{t}\right)\left(1-\tau_{k, t}\right)\right]
$$

Similarly, combining the first-order optimality condition of the consumer (14) with the equilibrium wage rate given by (8), we have in equilibrium:

$$
\left(1-\frac{1}{\varepsilon_{t}}\right) F_{l, t}\left(1-\tau_{l, t}\right) u_{c, t}=-u_{l, t}
$$

Conditions (15) and (16) are going to be useful when defining optimal taxes in Section 3.2.

Government budget balance. Government uses capital, labor, and profit income taxes $\left\{\tau_{k, t}, \tau_{l, t}, \tau_{\pi, t}\right\}_{t=1}^{\infty}$ to finance an exogenous stream of spending $\left\{g_{t}\right\}_{t=1}^{\infty}$ and initial debt $b_{1}$.

$$
\sum_{t=1}^{\infty} p_{t} g_{t}+p_{1} b_{1} \leq \sum_{t=1}^{\infty} p_{t}\left(w_{t} l_{t} \tau_{l, t}+\left(r_{t}-q_{t} \delta\right) k_{t} \tau_{k, t}+\pi_{t} \tau_{\pi, t}\right)
$$


Resource feasibility. Aggregate resource feasibility requires that for all $t \geq 1$

$$
c_{t}+q_{t} k_{t+1}+g_{t}=F_{t}\left(k_{t}, l_{t}\right)+(1-\delta) q_{t} k_{t}
$$

Tax-Distorted Market Equilibrium. Given $\left(k_{1}, b_{1}\right)$ and $\left\{g_{t}\right\}_{t=1}^{\infty}$, a tax-distorted market equilibrium is a policy $\left\{\tau_{k, t}, \tau_{l, t}, \tau_{\pi, t}\right\}_{t=1}^{\infty}$, an allocation $\left\{c_{t}, k_{t+1}, l_{t}\right\}_{t=1}^{\infty}$ and a price system $\left\{p_{t}, r_{t}, w_{t}\right\}_{t=1}^{\infty}$ such that:

1. Given policy and prices, allocation solves representative consumer's problem;

2. All firms maximize profits;

3. Markets for final and intermediate goods, capital, and labor clear;

4. Government's budget constraint is satisfied. ${ }^{8}$

\section{Optimal Tax Analysis}

Consider now the problem of a government who needs to finance a given stream of public spending. We assume that there is an institution or commitment technology through which the government can bind itself to a particular sequence of policies once and for all in period one. Once the policy is chosen, consumers and firms interact in capital, labor and goods markets according to the market equilibrium defined earlier. The government is sophisticated enough that it predicts that different government policies lead to different behavior of economic agents, which then leads to different market equilibria. There are possibly many policy sequences that can finance a given stream of government spending. Among these, the benevolent government chooses the one that maximizes the representative consumer's welfare.

It is well-known that in optimal tax problems of this sort, the government would like to set the tax rate on capital income in the very first period as high as possible since this tax is

\footnotetext{
${ }^{8}$ Notice that we do not need so specify resource feasibility as an equilibrium condition. This is because, under the assumptions we make about preferences, consumer's and government's budget constraints hold with equality, and these two imply resource feasibility.
} 
effectively a lump-sum tax on first period capital income. To make the problem interesting, we follow the literature and set the initial capital tax rate to an exogenous value, $\bar{\tau}_{k, 1}$.

Another assumption that we make about the set of tax instruments available to the government is that the tax rate on capital and profit income are the same in every period, i.e., $\tau_{\pi, t}=\tau_{k, t}$ for all $t$. We believe that this assumption is a reasonable one as it is hard for governments to distinguish profit income from capital income. This assumption is also broadly in line with actual tax policy practices in the United States and the developed economies. ${ }^{9}$ Therefore, the government chooses $\tau=\left\{\tau_{k, t+1}, \tau_{l, t}\right\}_{t=1}^{\infty}$. Formally, given $\left(k_{1}, b_{1}\right)$ and $\left\{g_{t}\right\}_{t=1}^{\infty}$, the optimal tax policy, $\tau^{*}$, solves the following optimal tax problem:

$$
\max _{\tau} \sum_{t=1}^{\infty} \beta^{t-1} u\left(c_{t}, l_{t}\right)
$$

subject to the fact that the tax system $\left\{\tau_{k, t}, \tau_{l, t}, \tau_{\pi, t}\right\}_{t=1}^{\infty}$, the allocation $\left\{c_{t}, k_{t+1}, l_{t}\right\}_{t=1}^{\infty}$ and the price system $\left\{p_{t}, r_{t}, w_{t}\right\}_{t=1}^{\infty}$ constitute a market equilibrium.

\subsection{Ramsey Allocation}

The optimal tax problem defined above is a fairly hard problem to solve directly as the constraint set involves endogenous prices, and consumer and firm maximization problems. Instead of attacking this problem directly, we are going to follow the primal approach which is a common way of solving optimal tax problems in the literature. In this approach, we solve the optimal tax problem in three steps. First, we show that the optimal tax problem is equivalent to a planning problem where the government chooses the allocation directly subject to a number of conditions that summarize all restrictions on allocations that is implied by the tax-distorted market equilibrium. This problem is called the Ramsey problem in the literature. Second, we characterize the Ramsey allocation, namely, the allocation that

\footnotetext{
${ }^{9}$ Although business income is taxed according to various tax laws according to the U.S. tax code - mainly the corporate, dividend and capitals gains taxes - none of these taxes treat capital and profit income as separate tax bases.
} 
solves the Ramsey problem, by a set of optimality conditions. Finally, we back out optimal tax rates by comparing optimality conditions that come out of the Ramsey problem and the tax-distorted competitive equilibrium. The following proposition deals with the first step of the primal approach. It establishes that the resource feasibility constraint together with two other constraints characterizes the tax-distorted market equilibrium completely.

Proposition 1. If an allocation $\left\{c_{t}, k_{t+1}, l_{t}\right\}_{t=1}^{\infty}$ is part of a tax-distorted market equilibrium, then it satisfies resource feasibility constraint (18), and the constraints (19) and (20) below. Conversely, suppose an allocation $\left\{c_{t}, k_{t+1}, l_{t}\right\}_{t=1}^{\infty}$ satisfies (18), (19) and (20). Then, we can construct prices and taxes such that this allocation together with constructed prices and taxes constitute an equilibrium allocation.

$$
\begin{gathered}
\sum_{t=1}^{\infty} \beta^{t-1}\left(u_{c, t} c_{t}+u_{l, t} l_{t}\right)=\sum_{t=1}^{\infty} \beta^{t-1} u_{c, t} \pi_{t}\left(1-\tau_{\pi, t}\right)+u_{c, 1}\left(\bar{r}_{1} k_{1}+b_{1}\right) \\
\tau_{\pi, t}=1-\frac{\frac{u_{c, t-1} q_{t-1}}{\beta u_{c, t}}-q_{t}}{\left(1-\frac{1}{\varepsilon_{t}}\right) F_{k, t}-\delta q_{t}}, \quad \forall t \geq 2 .
\end{gathered}
$$

Proof. Relegated to Appendix A.1.

The first constraint above, given by (19), is called the implementability constraint, and summarises all equilibrium conditions (except for resource feasibility). This is a standard constraint and a version of this is present in all Ramsey tax problems. The second constraint, given by (20), represents the restriction that profit income tax rate has to equal capital income tax rate, and follows from (15).

Ramsey problem. Given $\left(k_{1}, b_{1}\right)$, initial policies $\tau_{\pi, 1}=\tau_{k, 1}=\bar{\tau}_{k, 1}$, and a sequence of government spending, $\left\{g_{t}\right\}_{t=1}^{\infty}$, the government chooses allocation $(c, k, l)$ to solve the following 
problem:

$$
\begin{gathered}
\max _{c, k, l} \sum_{t=1}^{\infty} \beta^{t-1} u\left(c_{t}, l_{t}\right) \\
\text { s.t. } \\
c_{t}+q_{t} k_{t+1}+g_{t} \leq F_{t}\left(k_{t}, l_{t}\right)+(1-\delta) q_{t} k_{t}, \quad \text { for all } t \\
\sum_{t=1}^{\infty} \beta^{t-1}\left(u_{c, t} c_{t}+u_{l, t} l_{t}\right)=\sum_{t=1}^{\infty} \beta^{t-1} u_{c, t}\left(1-\tau_{\pi, t}\right) \pi_{t}+u_{c, 1}\left(\bar{r}_{1} k_{1}+b_{1}\right)
\end{gathered}
$$

where $\pi_{t}=\frac{1}{\varepsilon_{t}} F_{t}\left(k_{t}, l_{t}\right)$ and $\tau_{\pi, t}$ is given by $(20)$.

The first term on the right-hand-side of the implementability constraint, which involves terms related to profits, is the main difference between our problem and the standard Ramsey problem without profits. This term shows up in the Ramsey problem because there are profits in equilibrium. In fact, it is equal to the net-present-value of after-tax profit income in terms of period one consumption good. To see this notice that each period the amount of after-tax profits equals $\left(1-\tau_{\pi, t}\right) \pi_{t}$ in terms of period $t$ consumption good. To calculate the value of this in period one consumption good units, we multiply this by the shadow price of period-t consumption good in period-1 consumption good unit, that is by $p_{t}$, which is proportional to $\beta^{t-1} u_{c, t}$.

In the solution to this problem, the implementability constraint binds in the direction that the left-hand-side should be greater than the right-hand-side. In fact, an explicit derivation of this constraint from the government's budget constraint would reveal that the lefthand-side corresponds to the revenue side of government's budget while the right-hand-side corresponds to its spending. As such, the net-present-value of untaxed profits appear as a cost in the Ramsey problem. A brief intuition for this is that since taxing pure profits is not distortionary, Ramsey government would like to tax them at $100 \%$. When this is not possible, this is identical to a case where the government taxes profits at $100 \%$ but needs to give $\left(1-\tau_{\pi, t}\right)$ back to consumers. This is why after-tax profit income appears as a cost in 
the Ramsey problem.

Now, we derive the first-order optimality conditions of the government to see how the existence of profits change the Ramsey planner's marginal cost-benefit analysis of changing capital and labor. This is useful as it will help us understand the optimal tax formulas that come later on. Letting $\mu_{t}$ and $\lambda$ be the Lagrangian multipliers on period $t$ feasibility and implementability constraints, and the star allocation denote the Ramsey allocation, the first-order optimality condition for capital in any period $t \geq 2$ is:

$$
\begin{aligned}
\left(k_{t}\right):-\mu_{t-1}^{*} q_{t-1} & +\mu_{t}^{*}\left(F_{k, t}^{*}+(1-\delta) q_{t}\right) \\
& -\lambda^{*} \beta^{t-1} u_{c, t}^{*}\left[\left(1-\tau_{\pi, t}^{*}\right) \frac{\partial \pi_{t}^{*}}{\partial k_{t}}+\frac{\partial\left(1-\tau_{\pi, t}^{*}\right)}{\partial k_{t}} \pi_{t}^{*}\right]=0 .
\end{aligned}
$$

The two terms in the first line of (22) are standard. The first term represent the period $t-1$ physical cost of investing in period $t$ capital stock whereas the second term represents the period $t$ physical return on that investment. These two terms add up to a positive value, since, due to the presence of product market power, the social returns to investment, $F_{k, t}$, exceeds the private returns, $\left(1-\frac{1}{\varepsilon_{t}}\right) F_{k, t}$. This calls for a subsidy. The existence of profits in the implementability constraint, (19), introduces two new terms into the first-order condition of capital presented in the second line of (22). We now discuss these terms.

Indirect tax on profit income. The first term is:

$$
-\lambda^{*} \beta^{t-1} u_{c, t}^{*}\left(1-\tau_{\pi, t}^{*}\right) \frac{\partial \pi_{t}^{*}}{\partial k_{t}} .
$$

Recall that the net-present-value of untaxed profits enters as a cost to the Ramsey planning problem. Increasing capital in period $t$ increases after-tax profits in the same period, and as such, has an additional marginal cost. The rise in the net-present-value of untaxed profits equals the rise in after-tax profits in period $t,\left(1-\tau_{\pi, t}\right) \frac{\partial \pi_{t}}{\partial k_{t}}$, times the price of consumption in period $t, \beta^{t-1} u_{c, t}^{*}$. The multiplier on the implementability constraint, $\lambda^{*}$, measures the 
social value of an additional unit of public funds. This additional cost term implies a tax on capital income. Intuitively, since taxing profits is a lump-sum tax, government would like to tax profits away completely. When this is not possible, it is optimal to tax intermediate goods, capital in this case, since it acts as an indirect tax on profit income.

Direct tax on profit income. The second term in the second line of (22) is:

$$
-\lambda^{*} \beta^{t-1} u_{c, t}^{*} \frac{\partial\left(1-\tau_{\pi, t}^{*}\right)}{\partial k_{t}} \pi_{t}^{*}
$$

Notice that a higher level of period $t$ capital stock implies a lower marginal product of capital, which, through (20), implies a lower profit tax rate since $\frac{\partial\left(1-\tau_{\pi, t}^{*}\right)}{\partial k_{t}}>0$, which means that increasing capital increases the net-present-value of untaxed profits by the rise in after-tax profits in period $t$. The term $\lambda^{*} \beta^{t-1} u_{c, t}^{*}$ again translates this cost into the social value of public funds. This additional social cost of increasing capital introduces another reason for its taxation. Intuitively, since capital and profit income are taxed at the same rate, taxing capital income provides a direct way of taxing profit income, and this is beneficial since taxing profits is non-distortionary.

The first-order optimality condition for labor for $t \geq 2$ is:

$$
\begin{aligned}
\left(l_{t}\right): \beta^{t-1} u_{l, t}^{*}+\mu_{t}^{*} F_{l, t}^{*} & +\lambda^{*} \beta^{t-1}\left[u_{l l, t}^{*} l_{t}+u_{l, t}^{*}\right] \\
& -\lambda^{*} \beta^{t-1} u_{c, t}^{*}\left[\left(1-\tau_{\pi, t}^{*}\right) \frac{\partial \pi_{t}^{*}}{\partial l_{t}}+\frac{\partial\left(1-\tau_{\pi, t}^{*}\right)}{\partial l_{t}} \pi_{t}^{*}\right]=0 .
\end{aligned}
$$

The terms in the first line of (25) are standard terms present in the first-order condition for labor in standard Ramsey problems without profits. The two terms in the second line are new and appear due to the presence of the net-present-value of after-tax profit income on the right-hand-side of the implementability constraint, (19). The first term is negative, and is analogous to the indirect tax on profit income term for capital: increasing labor raises profits, and so has an additional social cost. The second term is positive, which means there 
is an additional benefit of increasing labor. Since $F_{k l}>0$, increasing labor is consistent with a higher tax on capital, and hence, profits in equilibrium. The first term calls for an additional tax while the second one calls for a subsidy on labor income.

The full characterization of the Ramsey allocation also includes the first-order optimality conditions with respect to consumption. This characterization is relegated to Appendix A. $2 .{ }^{10}$

\subsection{Optimal Taxes}

In this section, we provide formulas for optimal taxes that implement the Ramsey allocation in the market equilibrium defined in Section 2. We focus on steady-state tax formulas as the formulas for optimal taxes along the transition are quite complicated and do not add much to our understanding of the forces behind optimal taxes.

Defining optimal capital and labor income tax rates. Using (15) and (16) and defining the optimal tax rate on capital and labor income as the optimal distortions that implement Ramsey allocation in market equilibrium, we have

$$
\begin{aligned}
1-\tau_{k, t}^{*} & =\frac{\frac{u_{c, t-1}^{*} q_{t-1}}{\beta u_{c, t}^{*}}-q_{t}}{\left(\left(1-\frac{1}{\varepsilon_{t}}\right) F_{k, t}^{*}-\delta q_{t}\right)}, \\
1-\tau_{l, t}^{*} & =\frac{-u_{l, t}^{*}}{u_{c, t}^{*} F_{l, t}^{*}\left(1-\frac{1}{\varepsilon_{t}}\right)} .
\end{aligned}
$$

Steady-state tax formulas. Suppose the Ramsey allocation converges to a steady state. Let variables without a time subscript denote steady-state variables. Using the first-order optimality conditions of the Ramsey problem (21) and the definition of optimal taxes (26) and (27) at the steady state, one obtains the following optimal long-run tax formulas.

\footnotetext{
${ }^{10}$ The first-order optimality condition for labor in period 1 is different from (25) since first period profit tax rate is exogenous. For completeness, we provide this condition in Appendix A.2 as well.
} 
Proposition 2. The long-run optimal tax rate on capital and labor income are given by

$$
\tau_{k}^{*}=\frac{1}{\left(1-\frac{1}{\varepsilon}\right) F_{k}^{*}-\delta q}\left(-\frac{1}{\varepsilon} F_{k}^{*}+\chi^{*}\left[\frac{\partial \pi^{*}}{\partial k}\left(1-\tau_{\pi}^{*}\right)+\frac{\partial\left(1-\tau_{\pi}^{*}\right)}{\partial k} \pi^{*}\right]\right)
$$

and

$$
\tau_{l}^{*}=1-\frac{1+\lambda^{*}\left(1+\frac{u_{c c^{*} c^{*}}}{u_{c}^{*}}\right)}{1+\lambda^{*}\left(1+\frac{u_{l l}^{*} u_{l}^{*}}{u_{l}^{*}}\right)}\left(1-\chi^{*} \frac{1}{F_{l}^{*}}\left[\frac{\partial \pi^{*}}{\partial l}\left(1-\tau_{\pi}^{*}\right)+\frac{\partial\left(1-\tau_{\pi}^{*}\right)}{\partial l} \pi^{*}\right]\right) \frac{1}{1-\frac{1}{\varepsilon}},
$$

where $\chi^{*}=\frac{\lambda^{*} u_{c}^{*}}{\mu^{*}}$.

Proof. Combining steady-state versions of (22) and (26), and rearranging gives the capital tax formula. Combining steady-state versions of (25) and (27), and rearranging gives the labor tax formula.

Interpretting the capital tax formula. The optimal capital tax rate given by (28) is the multiplication of two terms. Recall that the government taxes capital income net of depreciation expenses, which equals $\left(\left(1-\frac{1}{\varepsilon}\right) F_{k}-\delta q\right) k$. The first term then is proportional to the inverse of the capital income tax base. Intuitively, all else equal, we need a higher tax rate to generate a given (optimal) distortion if the tax is applied to a smaller income base.

The second term is given by the summation of the two terms in the parenthesis. The first term equals $-\frac{1}{\varepsilon} F_{k}^{*}$. This term is negative and as such calls for a subsidy on capital income. Recall that the equilibrium of the growth model introduced in this paper features inefficiently low investment demand due to monopolistic distortions in the product market. Whenever the government cannot correct these distortions at the firm level directly via product market interventions, it is optimal to boost capital accumulation indirectly by subsidizing consumer savings. As we see in Section 4, when distortions are corrected on the production side of the economy where they originate, via product market policies, this term disappears from the optimal tax formula. 
The second term in the parenthesis represents the profit tax revenue benefit of taxing capital. First, when we increase taxes on capital income, this reduces after-tax profit income, and as such, provides an indirect tax on profits. The term $\frac{\partial \pi^{*}}{\partial k}\left(1-\tau_{\pi}^{*}\right)$ represents this benefit. Second, whenever profit and capital income are taxed at the same rate, increasing taxes on capital income also increases the tax rate on profit income, and as such, acts as a direct tax on profit income. The term $\frac{\partial\left(1-\tau_{\pi}^{*}\right)}{\partial k} \pi^{*}$ represents this benefit. Both the direct and the indirect profit tax revenue benefit of capital income taxation accrue in terms of higher government revenues. As such, this benefit must be weighted by the social value of public funds, $\lambda^{*} u_{c}^{*}$. On the other hand, the cost of taxing capital, which is the deadweight loss associated with slowing down capital accumulation, accrues in terms of lower output. The social cost of a unit of decline in output equals the multiplier on the resource constraint, $\mu^{*}$. The term, $\chi^{*}$, which we call the relative social value of public funds, translates the revenue benefit into the same unit as the deadweight loss, that is foregone output.

It is important to note that the term that calls for a subsidy, $-\frac{1}{\varepsilon} F_{k}^{*}$, would disappear if the profits accrued within a competitive framework, say, due to presence of factors of production that are in fixed supply. On the other hand, the indirect and direct tax terms remain intact as long as profits are pure economic rents, independent of the source of profit generation.

Interpretting the labor tax formula. The optimal labor tax rate given by (29) consists of three components. The first component, given by

$$
\frac{1+\lambda^{*}\left(1+\frac{u_{c c}^{*} c^{*}}{u_{c}^{*}}\right)}{1+\lambda^{*}\left(1+\frac{u_{l l}^{*} l^{*}}{u_{l}^{*}}\right)}<1,
$$


is the standard Ramsey labor tax component which is present irrespective of the existence of profits in equilibrium. The second component, given by

$$
\left(1-\chi^{*} \frac{1}{F_{l}^{*}}\left[\frac{\partial \pi^{*}}{\partial l}\left(1-\tau_{\pi}^{*}\right)+\frac{\partial\left(1-\tau_{\pi}^{*}\right)}{\partial l} \pi^{*}\right]\right),
$$

represents the profit tax revenue effects of labor taxes. Notice that whether this term calls for a tax or a subsidy on labor income is ambiguous as $\frac{\partial\left(1-\tau_{\pi}^{*}\right)}{\partial l}>0$. The third term, $\frac{1}{1-\frac{1}{\varepsilon}}>1$, represents the Pigouvian subsidy that is in place to correct for the underemployment arising from inefficiently low labor demand due to monopolistic competition.

\section{Optimal Taxes with Product Market Interventions}

The equilibrium of the growth model introduced in this paper features inefficiently low investment and labor demand due to the presence of monopolistic distortions in the product market. The inefficiently low capital and labor demand imply rental and wage rates that are lower than the corresponding marginal products, which, if not confronted with policy, gives rise to an equilibrium that features too little capital stock and labor. The analysis so far has not allowed the government to use product market interventions to correct distortions arising from monopolistic competition. In the absence of these policies, as we have seen in Section 3.2, there is a motive to subsidize consumer's capital and labor income in order to drive the equilibrium level of capital and labor up to the efficient level.

In this section, we consider a decentralization of the Ramsey allocation in which the problem of insufficient demand for inputs to production is dealt with via product market policies. We believe that this institutional design, where inefficiencies due to monopolistic competition are corrected at the product market, is a natural one since the insufficient demand originates in the product market. This is also in line with a growing literature that studies how to design product market policies in correcting inefficiencies stemming from 
market power. ${ }^{11}$ In the rest of the paper, we refer to the decentralization with product market policies as the baseline scenario.

Product market policies. We focus on a decentralization in which we enlarge the set of the government's fiscal policy tools to include product market policies. Specifically, government subsidizes the sales of intermediate goods producers at a flat rate. The level of the sales subsidy is chosen carefully to correct for the lack of demand for investment and employment that stem from monopoly distortions. This way capital and labor income taxation will only be concerned with raising revenue to finance government spending. At the same time, in order to keep the financing needs of the government identical to the case without product market interventions, government uses a lump-sum tax on intermediate goods producers to finance sales subsidies. This also leaves the equilibrium level of profit share in total income identical to the implementation without product market interventions.

Formally, let $\tau_{s, t}$ be the sales subsidy and $T_{t}$ be the lump-sum tax faced by intermediate goods producers in period $t$. The problem of the intermediate goods producers then is:

$$
\pi_{i, t}=\max _{\xi_{i, t}, y_{i, t}, k_{i, t}, l_{i, t}}\left(1+\tau_{s, t}\right) \xi_{i, t} y_{i, t}-r_{t} k_{i, t}-w_{t} l_{i, t}-T_{t} \quad \text { s.t. } \quad y_{i, t}=F_{t}\left(k_{i, t}, l_{i, t}\right) .
$$

The presence of product market policies also alter the government's budget constraint as follows:

$$
\sum_{t=1}^{\infty} p_{t}\left(g_{t}+\tau_{s, t} y_{t}\right)+p_{1} b_{1}=\sum_{t=1}^{\infty} p_{t}\left(w_{t} l_{t} \tau_{l, t}+\left(r_{t}-q_{t} \delta\right) k_{t} \tau_{k, t}+\pi_{t} \tau_{\pi, t}+T_{t}\right)
$$

The definition of equilibrium with product market policies is identical to the definition of market equilibrium given in Section 2 except that the intermediate goods producers' problem and government budget constraint are modified as above. The following proposition shows

\footnotetext{
${ }^{11}$ See, among others, Atkeson and Burstein (2019), Edmond, Midrigan, and Xu (2018), Boar and Midrigan (2020). The current paper is quite different from these papers in the sense that while our focus is on the optimal financing of government spending with income taxation they focus on correcting inefficiencies stemming from product market distortions.
} 
that any allocation that can be supported as an equilibrium without product market policies can also be supported as an equilibrium with product market policies in which (i) the rental rates of capital and labor equal their marginal products, (ii) the financing needs of the government and the profit share are the same as in the equilibrium without product market policies.

Proposition 3. Given $\left(k_{1}, b_{1}\right)$ and $\left\{g_{t}\right\}_{t=1}^{\infty}$, suppose the allocation $\left\{c_{t}, k_{t+1}, l_{t}\right\}_{t=1}^{\infty}$, together with prices $\left\{p_{t}, r_{t}, w_{t}\right\}_{t=1}^{\infty}$, profits $\left\{\pi_{t}\right\}_{t=1}^{\infty}$, and taxes $\left\{\tau_{k, t}, \tau_{l, t}, \tau_{\pi, t}\right\}_{t=1}^{\infty}$ constitute a tax-distorted market equilibrium without product market policies. Then, $\left\{c_{t}, k_{t+1}, l_{t}\right\}_{t=1}^{\infty}$ is an equilibrium allocation under product market policies $\tau_{s, t}=\frac{1}{\varepsilon_{t}-1}$ and $T_{t}=y_{t} \frac{1}{\varepsilon_{t}\left(\varepsilon_{t}-1\right)}$, for all $t$, with appropriately constructed prices and taxes. Moreover, in this equilibrium, profit income in each period $t$ equals $\hat{\pi}_{t}=\pi_{t}$, factor prices are given by $\hat{r}_{t}=F_{k, t}, \hat{w}_{t}=F_{l, t}$, and government budget constraint reduces to (19).

Proof. Relegated to Appendix A.3.

A key implication of Proposition 3 is that the Ramsey Problem is identical to the one given by (21) except that now the restriction that profit tax rate equals the tax rate on capital income takes the form

$$
\tau_{\pi, t}=1-\frac{\frac{u_{c, t-1} q_{t-1}}{\beta u_{c, t}}-q_{t}}{F_{k, t}-\delta q_{t}}, \quad \forall t \geq 2
$$

This is because now the equilibrium rental rate of capital that the representative consumer faces is equal to $F_{k, t}$ (instead of $\left(1-\frac{1}{\varepsilon}\right) F_{k, t}$ ). Formally, the Ramsey problem is defined as follows.

Ramsey problem. Given $\left(k_{1}, b_{1}\right)$, initial policies $\tau_{\pi, 1}=\tau_{k, 1}=\bar{\tau}_{k, 1}$, and a sequence of government spending, $\left\{g_{t}\right\}_{t=1}^{\infty}$ government chooses allocation $(c, k, l)$ to solve the following 
problem:

$$
\begin{gathered}
\max _{c, k, l} \sum_{t=1}^{\infty} \beta^{t-1} u\left(c_{t}, l_{t}\right) \\
\text { s.t. } \\
c_{t}+q_{t} k_{t+1}+g_{t} \leq F_{t}\left(k_{t}, l_{t}\right)+(1-\delta) q_{t} k_{t}, \quad \text { for all } t \\
\sum_{t=1}^{\infty} \beta^{t-1}\left(u_{c, t} c_{t}+u_{l, t} l_{t}\right)=\sum_{t=1}^{\infty} \beta^{t-1} u_{c, t}\left(1-\tau_{\pi, t}\right) \pi_{t}+u_{c, 1}\left(\bar{r}_{1} k_{1}+b_{1}\right),
\end{gathered}
$$

where $\pi_{t}=\frac{1}{\varepsilon_{t}} F_{t}\left(k_{t}, l_{t}\right)$ and $\tau_{\pi, t}$ is given by $(31)$.

Defining optimal capital and labor income tax rates. The optimal tax on capital and labor income that implement Ramsey allocation in the market equilibrium with product market interventions are given by:

$$
\begin{aligned}
1-\tau_{k, t}^{*} & =\frac{\frac{u_{c, t-1}^{*} q_{t-1}}{\beta u_{c, t}^{*}}-q_{t}}{F_{k, t}^{*}-\delta q_{t}}, \\
1-\tau_{l, t}^{*} & =\frac{v_{l, t}^{*}}{u_{c, t}^{*} F_{l, t}^{*}} .
\end{aligned}
$$

These optimal tax definitions reflect the fact that, in the presence of product market interventions, the rental and wage rates equal the corresponding marginal products. As we will see, this implies that implementing the Ramsey allocation in the equilibrium with product market policies do not require Pigouvian subsidies on capital and labor income.

Proposition 4. The long-run optimal tax rate on capital and labor income are given by

$$
\tau_{k}^{*}=\frac{1}{F_{k}^{*}-\delta q} \chi^{*}\left[\frac{\partial \pi^{*}}{\partial k}\left(1-\tau_{\pi}^{*}\right)+\frac{\partial\left(1-\tau_{\pi}^{*}\right)}{\partial k} \pi^{*}\right]
$$

and

$$
\tau_{l}^{*}=1-\frac{1+\lambda^{*}\left(1+\frac{u_{c c^{*}}^{*}}{u_{c}^{*}}\right)}{1+\lambda^{*}\left(1+\frac{u_{l l}^{*} l^{*}}{u_{l}^{*}}\right)}\left(1-\chi^{*} \frac{1}{F_{l}^{*}}\left(\frac{\partial \pi^{*}}{\partial l}\left(1-\tau_{\pi}^{*}\right)+\frac{\partial\left(1-\tau_{\pi}^{*}\right)}{\partial l} \pi^{*}\right)\right),
$$


where $\chi^{*}=\frac{\lambda^{*} u_{c}^{*}}{\mu^{*}}$ is the relative social value of public funds.

Proof. Combining steady-state versions of (22) and (33), and rearranging gives the capital tax formula. Combining steady-state versions of (25) and (34), and rearranging gives the labor tax formula.

The main difference of the optimal capital tax rate with product market interventions given by (35) relative to the optimal capital tax rate without such policies given by (28) is that in the latter formula there is an additional term, $-\frac{1}{\varepsilon} F_{k}^{*}$, that calls for a subsidy on capital income. This component is absent in (35) since in this case monopolistic distortions are already dealt with at the firm level where they originate. For this reason, we expect that the optimal capital tax rate is higher in the case with product market policies. ${ }^{12}$ For the same reason, the formula for the optimal labor tax rate in the case without product market subsidies, given by (29), features an additional subsidy term, $\frac{1}{1-\frac{1}{\varepsilon}}$, that is not present in the formula given by (36).

\subsection{Lower Bound on the Optimal Capital Tax Rate}

The capital tax formula (35) is useful because it provides an intuitive explanation of the various components of the optimal tax. However, (35) is also quite complicated and depends on the optimal tax rate on capital itself. In this section, we derive an alternative version of the optimal capital tax formula, which allows us to provide a lower bound on the optimal tax rate that depends on empirically estimable parameters.

By taking the terms inside the bracket on the right-hand side of $(35)$ into $\left(1-\tau_{\pi}^{*}\right)$ parenthesis and using $\tau_{\pi}^{*}=\tau_{k}^{*}$, we obtain the following formula for optimal capital income tax rate

$$
\frac{\tau_{k}^{*}}{1-\tau_{k}^{*}}=\frac{F_{k}^{*}}{F_{k}^{*}-\delta q} \chi^{*} S_{\pi}\left[1+\frac{\mathcal{E}_{1-\tau_{k}, k}^{*}}{\mathcal{E}_{y, k}^{*}}\right],
$$

\footnotetext{
${ }^{12}$ There is an additional, more subtle difference between the two optimal capital tax formulas. To see this, notice that the first term on the right-hand-side of $(28)$ has an additional $\left(1-\frac{1}{\varepsilon}\right)$ multiplying $F_{k}^{*}$. The difference is due to the fact that rental rate on capital equals $\left(1-\frac{1}{\varepsilon}\right) F_{k}^{*}$ in the environment without product market policies while it is equal to $F_{k}^{*}$ in the environment with.
} 
where $\mathcal{E}_{1-\tau_{k}, k}^{*}=\left.\frac{d \ln \left(1-\tau_{k}\right)}{d k}\right|_{k=k^{*}}$ is the elasticity of the retention rate on capital income with respect to the equilibrium level of capital stock and $\mathcal{E}_{y, k}^{*}=\left.\frac{d \ln y}{d k}\right|_{k=k^{*}}$ is the elasticity of national income with respect to the capital stock. When $\mathcal{E}_{1-\tau_{k}, k}^{*}$ is larger, the retention rate is more sensitive to the equilibrium level of capital stock. In other words, a unit decrease in capital stock requires a larger decrease in the retention rate of capital, and hence profit, income. This means the direct tax channel is stronger, which implies that the benefits of taxing capital is higher. This is why higher $\mathcal{E}_{1-\tau_{k}, k}^{*}$ implies a higher optimal capital tax rate. The tax rate is decreasing in $\mathcal{E}_{y, k}^{*}$ because the deadweight loss of increasing capital taxes, and hence, reducing capital stock depends on the elasticity of output with respect to capital stock.

Although intuitive, these elasticity concepts are hardly useful when calculating the optimal tax rate since especially the elasticity of the retention rate with respect to the equilibrium level of capital stock is quite hard to estimate from the data. Fortunately, we can use the following transformation:

$$
\frac{\mathcal{E}_{1-\tau_{k}, k}^{*}}{\mathcal{E}_{y, k}^{*}}=\frac{1}{\mathcal{E}_{k, 1-\tau_{k}}^{*} \mathcal{E}_{y, k}^{*}}=\frac{1}{\mathcal{E}_{y, 1-\tau_{k}}^{*}},
$$

where $\mathcal{E}_{y, 1-\tau_{k}}^{*}$ is the elasticity of national income with respect to the tax rate on capital income. Plugging this back into (37), we obtain

$$
\frac{\tau_{k}^{*}}{1-\tau_{k}^{*}}=\frac{F_{k}^{*}}{F_{k}^{*}-\delta q} \chi^{*} S_{\pi}\left[1+\frac{1}{\mathcal{E}_{y, 1-\tau_{k}}^{*}}\right]
$$

This optimal tax formula shows, perhaps quite intuitively, that when the elasticity of national income with respect to the retention rate is larger, the optimal capital tax rate is lower. In other words, when national income is more sensitive to the tax rate on capital, the latter ought to be lower. A merit of this formula is that the elasticity of national income with respect to the capital income tax rate is, in principle, estimable. Since $\delta q>0,(38)$ immediately implies the following corollary. 
Corollary 1. The optimal long-run tax rate on capital income satisfies:

$$
\tau_{k}^{*}>\frac{1}{1+\left(\chi^{*} S_{\pi}\right)^{-1}\left(1+\mathcal{E}_{y, 1-\tau_{k}}^{*-1}\right)^{-1}} .
$$

The lower bound on the optimal capital income tax is increasing in the relative social value of public funds, $\chi^{*}$, and the profit share, $S_{\pi}$. These are intuitive: (i) a higher relative value of social funds means the revenue benefit of taxation is weighted more than its resource cost; (ii) both the direct and the indirect profit tax revenue benefits of capital taxation are proportional to the profit share. Moreover, the lower bound is decreasing in the sensitivity of national income with respect to the capital tax rate.

Corollary 1 is useful because, given the empirical knowledge of the relative social value of public funds, $\chi^{*}$, the share of profits, $S_{\pi}$, and the elasticity of national income with respect to the capital tax rate (at the optimum), it provides a lower bound on the optimal capital tax rate without knowing the details of the other structural parameters of the model, such as the production function and preference parameters. An alternative approach is to make further structural assumptions, which helps us to reduce the lower bound on the capital tax rate to the structural parameters of the model, and then use estimates of these parameters to gauge a lower bound (at the expense of making the model more specific). This is what the next proposition does.

Proposition 5. Suppose $u(c, l)=\frac{c^{1-\sigma}}{1-\sigma}-v(l)$, where $v^{\prime}, v^{\prime \prime}>0$, and $F=A k^{\alpha} l^{1-\alpha}$. The optimal long-run tax rate on capital income satisfies:

$$
\tau_{k}^{*}>\frac{1}{1+\left(\lambda^{*^{-1}}+1-\sigma\right) \varepsilon \alpha} .
$$

Proof. Relegated to Appendix A.4.

All the parameters in this lower bound, with the exception of $\lambda^{*}$, the social value of public funds, are structural. Therefore, the proposition gives us a lower bound on the optimal long- 
run capital tax rate provided that we have an estimate of the social value of public funds.

\subsection{Zero Profit Income Benchmark}

Notice that since $\pi^{*}$ and $\frac{\partial \pi^{*}}{\partial k}$ are proportional to the profit share in national income $S_{\pi}$, the optimal long-run tax rate on capital income given by (35) is also proportional to the profit share. In particular, whenever the profit share is zero, so is the optimal tax on capital income in the steady state. The optimal long-run labor income tax rate reduces to the standard Ramsey component in this case. The following corollary summarizes this result.

Corollary 2. If $S_{\pi}=0$, then $\tau_{k}^{*}=0$ and $\tau_{l}^{*}=1-\frac{1+\lambda^{*}\left(1+\frac{u_{c}^{*} c^{*}}{u_{c}^{*}}\right)}{1+\lambda^{*}\left(1+\frac{u_{l l}^{*} l^{*}}{u_{l}^{*}}\right)}>0$.

The following proposition establishes a more general result about optimality of not taxing capital that holds along the transition as well. ${ }^{13}$

Proposition 6. Suppose $u(c, l)=\frac{c^{1-\sigma}}{1-\sigma}-v(l)$, where $v^{\prime}, v^{\prime \prime}>0$. If in some period $t \geq 3$, we have $S_{\pi, t-1}=S_{\pi, t}=S_{\pi, t+1}=0$. Then, $\tau_{k, t}^{*}=0$ and $\tau_{l, t}^{*}=1-\frac{1+\lambda^{*}\left(1+\frac{u_{c c, t}^{*} c_{t}^{*}}{u_{c, t}^{*}}\right)}{1+\lambda^{*}\left(1+\frac{u_{l l, t}^{*} t_{t}^{*}}{u_{l, t}^{*}}\right)}>0$.

Proof. Relegated to Appendix A.5.

In particular, the proposition implies that in an economy where the share of profits in national income is zero, the optimal tax rate on capital is also zero in the short and the long run. ${ }^{14}$ An important implication of this result is that if we live in a competitive economy and the decline in labor share is occurring due to a rise in capital share, then the lessons from classical Ramsey tax theory apply: it is optimal to set capital tax rate to zero and finance government spending with (higher) taxes on labor income. Notice that this conclusion is independent of the exact mechanism behind the rise in capital share.

\footnotetext{
${ }^{13}$ Although in this section, we derive this result for the optimal tax analysis in the presence of product market interventions, the result also holds for the institutional setup of Section 3 which implements the Ramsey allocation without product market policies.

${ }^{14}$ The proposition states that the capital tax rate is zero from third period onward. Recall that the tax rate on the first period capital is a lump-sum tax, and hence, is exogenously set. It is a standard result in optimal Ramsey tax theory that the tax rate on the second period capital is qualitatively different from the tax rate on future periods, and is generally very high when there is no upper bound on capital income taxes.
} 


\section{Quantitative Analysis}

This section provides the discussion about the calibration of the model and simulation results.

\subsection{Calibration: Initial Steady State}

We choose parameters of the economy for the initial steady state (for the period before the decline in labor share has started: pre-1982) so that the model matches US economy along selected key moments for this time period. To complete this step, we need a code that solves for the steady state equilibrium of the economy, and an outer loop that executes calibration.

Table 1. Parameter Values - Calibration to 1982

\begin{tabular}{|c|c|c|c|}
\hline & Symbol & Value & Source/Target* \\
\hline \multicolumn{4}{|l|}{ Preferences } \\
\hline Discount Factor & $\beta$ & 0.96 & Target Risk Free Rate $=4.1 \%$ \\
\hline CRRA Parameter & $\sigma$ & 1.00 & - \\
\hline Labor Supply Elasticity Parameter & $\phi$ & 1.33 & Chetty et al. (2011) \\
\hline The Disutility of Hours Worked & $\psi$ & 9.65 & Target Labor Supply $=1 / 3$ \\
\hline \multicolumn{4}{|l|}{ Production } \\
\hline Elasticity of Substitution Parameter (between capital and labor) & $\rho$ & 0.20 & KN (2014) \\
\hline Capital Augmenting Technology Parameter & $A_{K}$ & 1.0 & Normalization \\
\hline Labor Augmenting Technology Parameter & $A_{L}$ & 1.0 & Normalization \\
\hline Depreciation Rate & $\delta$ & 0.072 & BEA \\
\hline Capital-Share Parameter & $\alpha_{K}$ & 0.295 & BLS \\
\hline Labor-Share Parameter & $\alpha_{L}$ & 0.705 & Target Labor Share $=64 \%$ (BLS) \\
\hline Elasticity of Substitution Parameter (between intermediate inputs) & $\varepsilon$ & 100 & Target Pofit Share $=1 \%$ (Barkai 2019) \\
\hline Relative Price of Investment & $q$ & 1 & Normalization \\
\hline \multicolumn{4}{|l|}{ Government Policy } \\
\hline Tax Rate on Labor Income & $\tau_{l}$ & $29 \%$ & MGP (2010) \\
\hline Tax Rate on Capital Income & $\tau_{k}$ & $40 \%$ & MGP (2010) \\
\hline Tax Rate on Profits & $\tau_{\pi}$ & $40 \%$ & MGP (2010) \\
\hline Government Expenditure & $g / y$ & 0.20 & St. Louis FED \\
\hline Government Debt & $b / y$ & 0.31 & St. Louis FED \\
\hline
\end{tabular}

* The acronyms KN and MGP stand for Karabarbounis and Neiman (2014) and McGrattan and Prescott (2010), respectively. BLS and BEA stand for Bureau of Labor Statistics and Bureau of Economic Analysis, respectively. 
Preferences. The model is calibrated on an annual basis and the full set of parameters, targets and sources is summarized in Table 1 . The discount factor $\beta$ is set to 0.96 so that the model implied real interest rate is equal to 4.1\% (Atkeson and Kehoe (2005)). The momentary utility function of the household takes the standard constant elasticity of intertemporal substitution form of

$$
u(c, l)=u(c)-v(l)=\frac{c^{1-\sigma}}{1-\sigma}-\psi \frac{l^{1+\phi}}{1+\phi} .
$$

The coefficient $\sigma$ is set to 1.00 as in line with the literature. The labor supply elasticity parameter $\phi$ is set to 1.33 , which implies a Frisch elasticity of aggregate hours of 0.75 as in Chetty, Guren, Manoli, and Weber (2011). The parameter that captures the disutility of hours worker $\psi$ is calibrated so that one third of available time is spent at work.

Production. The production function operated by intermediate goods producers is given by

$$
F_{t}\left(k_{t}, l_{t}\right)=\left(\alpha_{k, t}\left(A_{k, t} k_{t}\right)^{\rho}+\alpha_{l, t}\left(A_{l, t} l_{t}\right)^{\rho}\right)^{1 / \rho}
$$

The elasticity of substitution between capital and labor is captured by the parameter $\rho$ and is set to 0.20 as in Karabarbounis and Neiman (2014). The capital-augmenting and laboraugmenting technology parameters - $A_{K}$ and $A_{L}$ - are normalized to one, without loss of generality. The capital depreciation rate $\delta$ is set to 0.072 , which is equal to its pre-1982 level (over the period 1970-1982), calculated from BEA National Income and Product Accounts (NIPA) and BEA Fixed Asset Tables (FA). The labor share parameter $\alpha_{L}$ is internally calibrated to match the observed share of labor income for the U.S. nonfarm business sector over the period of 1947-1982, based on Bureau of Labor Statistics (BLS) data. Accordingly, the capital share parameter is $\alpha_{K}$ is set to $1-\alpha_{L}$. The relative price of investment $q$ is fixed and normalized to one, without loss of generality. This seems to be in line with the observed constancy in the relative price of investment over the period of 1947-1982, which also is 
documented by Karabarbounis and Neiman (2014) for the U.S. economy over the period of interest. ${ }^{15}$ The parameter that governs the elasticity of substitution between intermediate inputs $\varepsilon$ is set to 100 , implying a profit share of $1 \%$ which matches with the profit share findings of De Loecker, Eeckhout, and Unger (2019) for the early 1980's and also in line with the findings of Barkai (2019).

Government policy. The tax rates for the pre-1982 period are taken from McGrattan and Prescott (2010). Accordingly, we set tax rates on capital income $\tau_{k}$, labor income $\tau_{l}$ and profits $\tau_{\pi}$ equal to $40 \%, 29 \%$ and $40 \%$, respectively. The level of government expenditure is calibrated to match a government expenditure to GDP ratio of 0.20 , which is equal to its observed pre-1982 level calculated by using the St. Louis FED FRED data.

\subsection{Calibration: The Evolution of the Economy}

In this section, we discuss how the time-varying model inputs are calibrated. At this calibration stage, we assume that the tax rates change exogenously over the period of interest, as in line with their observed values in data. Recall that these tax rates are taken exogenous only at the calibration stage and will be endogenous in the optimal Ramsey problem.

There are 5 time-varying inputs in the model $-q, \tau_{k}, \tau_{\pi}, \varepsilon$ and $\alpha_{K}$ (or in other words $\left.1-\alpha_{L}\right)$ - that are displayed in Figure 2 and Figure 3. Figure 2 displays the exogenous timevarying inputs $\left(q, \tau_{k}, \tau_{\pi}\right)$ which are captured directly from the data. As discussed above, the tax rate on profits cannot be directly observed in the data since it is difficult to distinguish some profit categories from capital income. In line with this observation, in our benchmark calibration, we assume that the tax rate on profits is equal to the capital income tax rate observed in the data (Figure 2). Because we want to abstract from business cycle variations, the time-varying tax inputs are smoothed with piecewise linear series. In a similar fashion,

\footnotetext{
${ }^{15}$ As in Karabarbounis and Neiman (2014), we construct the relative price of investment series by calculating the ratio of the investment price deflator to the consumption price deflator for the U.S. economy over the post-war period. When we take a closer look at this price series, we observe that while the relative price of investment is quite constant till 1982, it started to decline in 1983.
} 
we fit a smooth polynomial form to match the change in price $q$ over the period of interest, which captures the fact that (i) the decline in relative price of investment starts in 1983 and (ii) the rate of decline slows down through the end, which implicitly implies that the declining trend in $q$ is expected to vanish before 2050s (Figure 2).

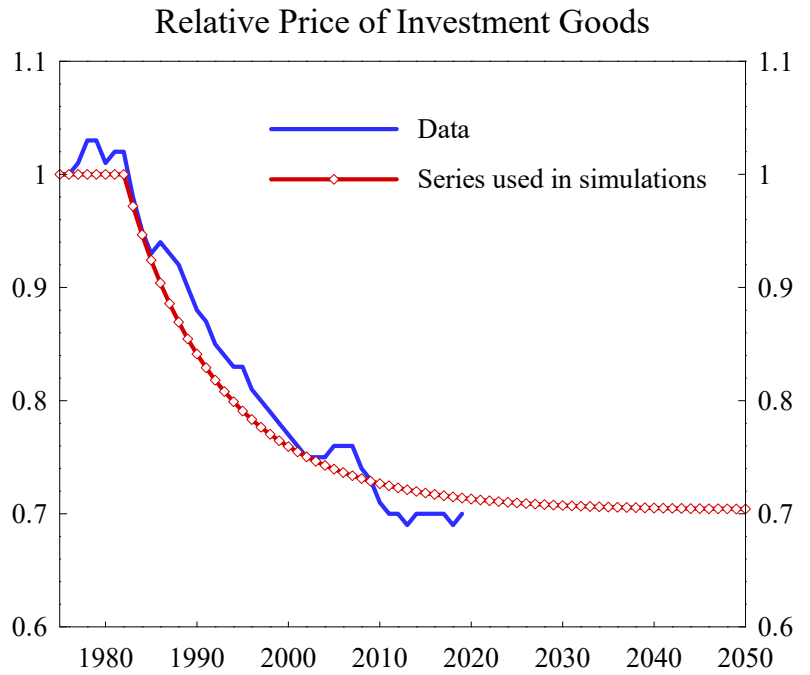

Figure 2: (a)
Capital Income Tax Rate

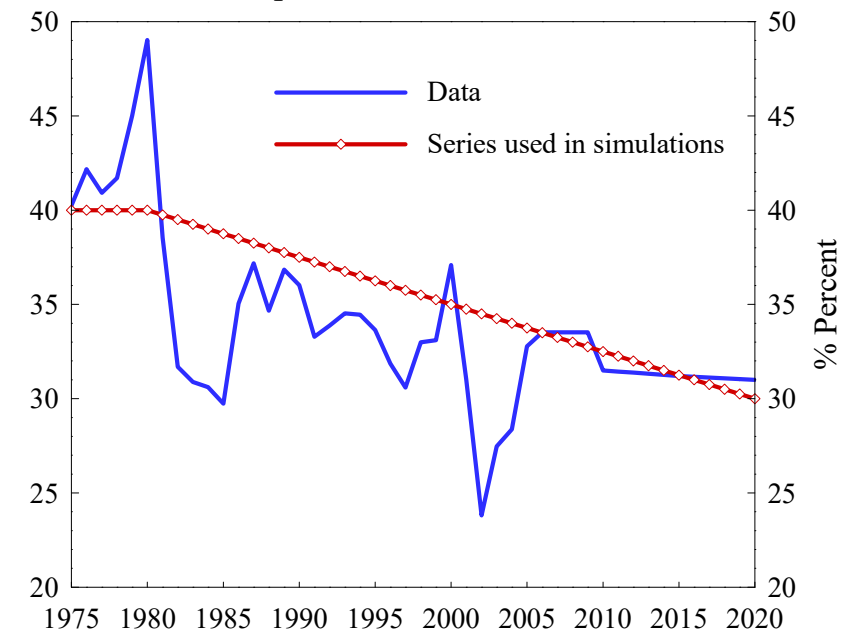

Figure 2: (b)

This figure depicts the time series for the relative price of investment goods (a) and the capital income tax rate (b) for the U.S. economy.

The remaining two time-varying parameters $-\varepsilon$ and $\alpha_{K}$ - needs to be calibrated endogenously in our setup, which needs a discussion. In our model, the $\varepsilon$ parameter generates the profit share in the economy and, therefore, play a crucial role. For the change in $\varepsilon$ over the period of 1983-2020, we consider the findings from the literature. Barkai (2019) finds that the profit share in the U.S. economy increased roughly by 13.5 percentage points over the period of 1984-2014. And in a recent paper, Barkai and Benzell (2018) documents that the profit share increased roughly from a level of $1 \%$ to $15 \%$ over the period of interest. These findings seem to be in line with the findings of other notable contributions in the literature. According to De Loecker, Eeckhout, and Unger (2019), the profit share for the U.S. economy increased approximately from $2 \%$ in the early-1980s to a level of $16 \%$ in the late-2010s. Eg- 
gertsson, Robbins, and Wold (2018) argues that the profit share, which was roughly zero in the early 1980 's, increased to a level of $17 \%$ by $2015 .{ }^{16}$ In line with these studies, we calibrate the changes in $\varepsilon$ parameter so that (i) the profit share in simulated economy increases from $1 \%$ to $15 \%$ and (ii) the time-series dynamics of simulated profit share series matches the one observed in the data. Finally, the last time-varying input of our model $-\alpha_{K}$ - is calibrated to match the observed change in labor income share over the post-1982 period. Recall that, in fact all time-varying inputs will have an affect on labor income share and, therefore, $\alpha_{K}$ is calibrated as the final time-varying input to match the observed decline in labor income share. Figure 3 displays these two calibrated time-varying series $\left(\varepsilon\right.$ and $\left.\alpha_{K}\right)$ used in our simulations.

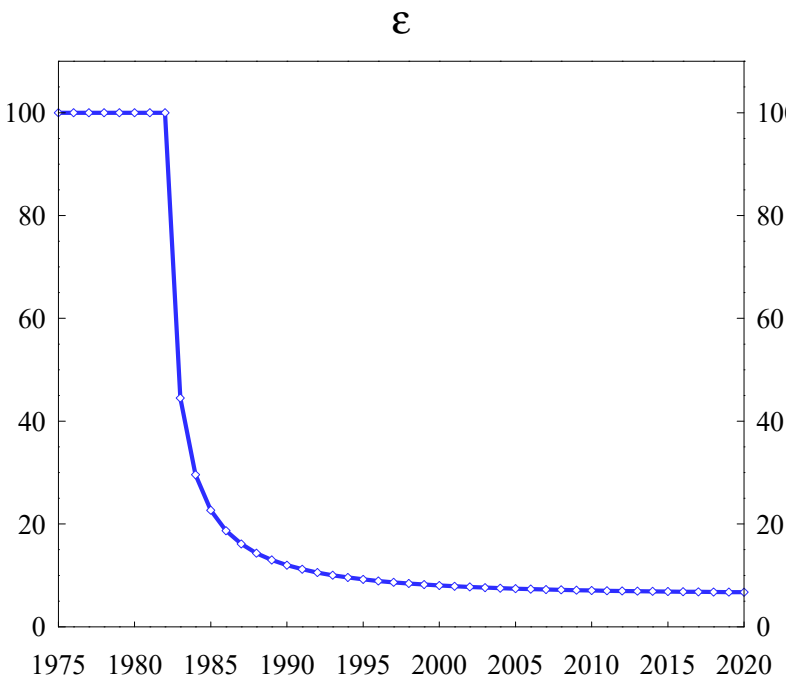

Figure 3: (a)

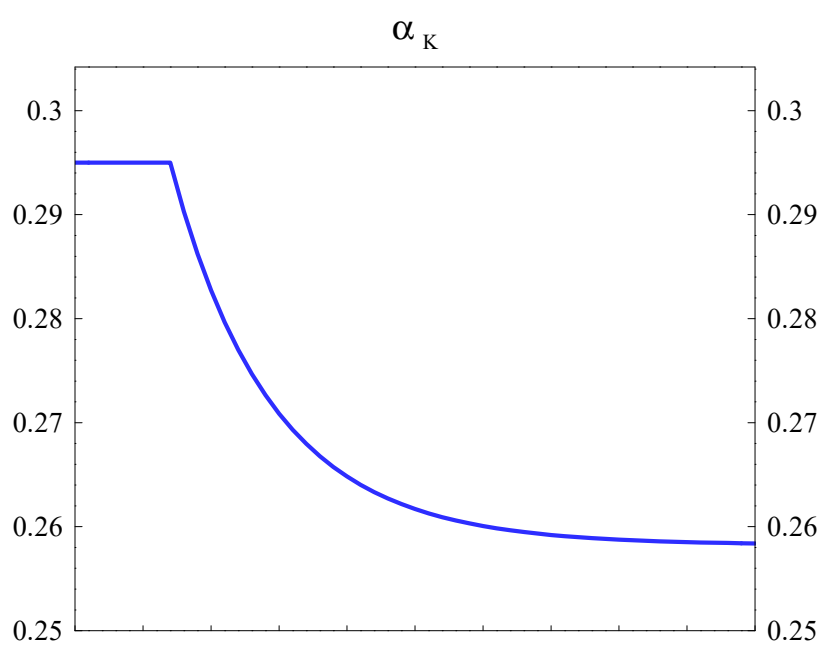

19751980198519901995200020052010201520202025

This figure depicts the calibrated time series of the model parameters $\varepsilon$ (a) and $\alpha_{K}$ (b).

At this point, after the calibration of endogenous time-varying variables, we want to discuss how well does model fit to data. Figure 4 displays the simulated time-series for profit share and labor share, as well as their counterparts in data. ${ }^{17}$ The simulated series

\footnotetext{
${ }^{16}$ Similarly, Karabarbounis and Neiman (2018) document that while the labor share and the capital share summed up to 1 in the early 1980's, this number fell down to 0.85 over the period of interest.

${ }^{17}$ The data on the evolution of profit shares is from Karabarbounis and Neiman (2018). The evolution of U.S. nonfarm labor share is calculated from Bureau of Economic Analysis (BEA) NIPA Tables.
} 
seems to be tracking the observed changes in profit and labor shares reasonably well over the period of interest. The data shows that the profit shares (i) started to increase in the early 1980s, (ii) reached roughly to a level of $15 \%$ in the 2000 s, and (iii) the pace of increase seems to be slowing down over the past decade. We find that the simulated profit shares can capture these three features. Similarly, the model can capture the long-run declining trend in labor share quite well, even though the labor share data seems to be disturbed by cyclical fluctuations. ${ }^{18}$

A. Profit Share (Data vs. Model)

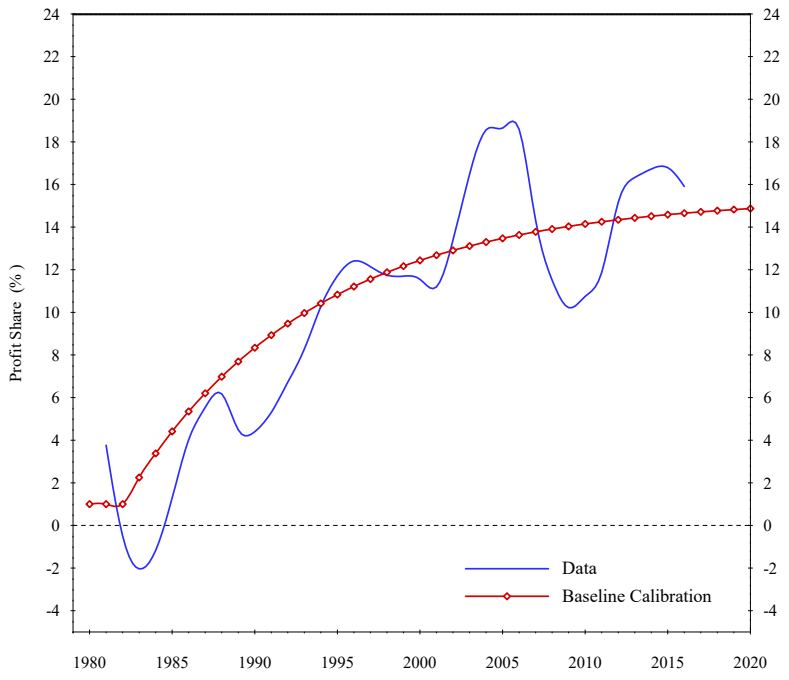

Figure 4: (a)
B. Labor Share (Data vs. Model)

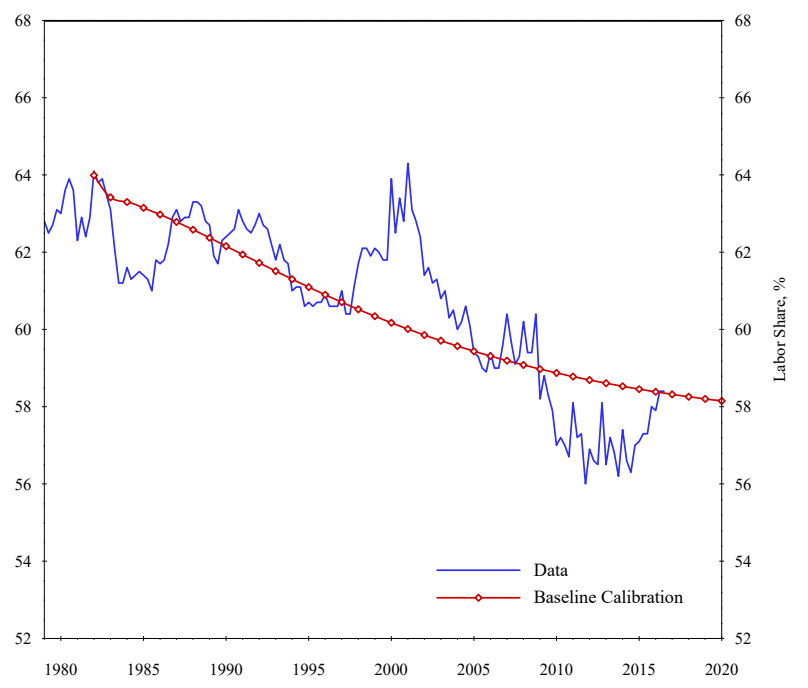

Figure 4: (b)

This figure depicts the time series of the observed and model implied profit share (a) and labor share (b).

APK- $\tilde{R}$. Caballero, Farhi, and Gourinchas (2017), among others, document that a key macroeconomic trend in the US economy observed during the period of interest has been the growing divergence between the return on productive capital and the return on safe assets. More specifically, they show that the difference between the Average Product of Capital

\footnotetext{
${ }^{18}$ Figure 3 shows that the decline in $\alpha_{K}$ values is captured by a smooth monotonic polynomial function. In order to track the observed decline in labor share better, one can assume that the $\alpha_{K}$ values can change with a non-monotonic fashion. However, we believe the cyclical fluctuations observed in the labor share data is beyond the scope of this paper.
} 
$(A P K)$ and the return on government bonds $(\tilde{R})$ has increased significantly since the 1980's. In this section, we test the validity of our calibration by investigating how our calibrated model performs in terms of matching this untargeted data moment.

$A P K$ adds up after-tax rental income and profits, net of depreciation, relative to the capital stock:

$$
A P K_{t}=\frac{\left(r_{t}-\delta_{t} q_{t}\right) K_{t}\left(1-\tau_{k, t}\right)+Y_{t} \frac{1}{\varepsilon_{t}}\left(1-\tau_{\pi, t}\right)}{q_{t-1} K_{t}},
$$

where $r_{t}=F_{K, t}\left(1-\frac{1}{\varepsilon_{t}}\right)$. Consumer indifference between investment in capital and government bonds requires:

$$
\tilde{R}_{t}=\frac{q_{t}-q_{t-1}}{q_{t-1}}+\left(1-\tau_{k, t}\right) \frac{r_{t}-\delta_{t} q_{t}}{q_{t-1}},
$$

where $\tilde{R}_{t}$ is the net return on government bond. Plugging (43) in (42), we get a condition between average return to capital $A P K$ and net real interest rate on government bond $\tilde{R}$, both of which are empirically measurable:

$$
A P K_{t}-\tilde{R}_{t}=\frac{q_{t-1}-q_{t}}{q_{t-1}}+\frac{Y_{t} \frac{1}{\varepsilon_{t}}\left(1-\tau_{\pi, t}\right)}{q_{t-1} K_{t}} .
$$

We can see from (44) that higher markups leads to an increase in $A P K-\tilde{R}$. Moreover, $A P K-\tilde{R}$ increases also when (i) the decline in equipment prices decelerates, and (ii) with any change that would increase $Y / K$. In our two alternative calibrations, we find that the dominant factor that affects $A P K-\tilde{R}$ turns out to be the change in markups. Table 2 shows the $A P K-\tilde{R}$ generated by our model as well as its counterpart in data. In the data, while $A P K-\tilde{R}$ was about $-0.4 \%$ in 1982 , it reached roughly to a level of almost $7.5 \%$ in $2020{ }^{19}$ In our model economy, while $A P K-\tilde{R}$ is $0.2 \%$ in 1982 , it increases to a level of $5.4 \%$ in $2020 .{ }^{20}$

\footnotetext{
${ }^{19}$ The data on $A P K$ series are generated for the US corporate sector based on BEA NIPA and Fixed Asset Tables and the methodology closely follows Caballero, Farhi, and Gourinchas (2017). Our baseline measure of $\tilde{R}$ is equals to the nominal rate on 10-year U.S. Treasuries minus 5-year moving average of realized inflation that proxies expected inflation, as in Karabarbounis and Neiman (2018).

${ }^{20}$ Equation (44) shows that lower levels of $\tau_{\pi, t}$ implies higher levels of $A P K-\tilde{R}$. In line with this, we will show in the following sections that the level of increase in simulated $A P K-\tilde{R}$ turns out to be higher in the alternative calibration in which the level of decrease in $\tau_{\pi, t}$ is assumed to be higher.
} 
We conclude that our calibrated model performs well in matching the rise in the divergence of return to productive capital and returns to safe assets. One way to interpret this finding is that the rise in market power by itself can be a major factor in explaining this divergence, which is is in line with Eggertsson, Robbins, and Wold (2018) and Farhi and Gourio (2018).

$\begin{gathered}\text { Table 2. APK-r (Data vs. Simulations) } \\
\text { Baseline Case }\end{gathered}$
\begin{tabular}{ccc} 
& \multicolumn{3}{c}{1982} & 2020 \\
\hline \hline Data & $-0.4 \%$ & $7.5 \%$ \\
Model & $0.2 \%$ & $5.4 \%$ \\
\hline \hline
\end{tabular}

\subsection{Optimal Taxes with Product Market Policies}

In this section, we report optimal capital and labor income taxes. We consider two distinct optimal tax reforms. In the first one, the government reforms the tax system now (the year 2021). This exercise, which, in short, will be referred to as "2021 reform", aims to inform the policymakers about the following question: given the observed decline in labor share and the tax policies in place up until now, what is the current optimal policy response? In our second exercise, we assume that the planner solves for the optimal taxes starting 1983. This analysis, which, in short, we refer to as "1983 reform", informs us about what the optimal reaction to declining labor share would have been had the government anticipated the decline in labor share and reformed the tax system in 1983. A comparison of the two reforms will be informative about the cost of postponing the optimal tax reform. In all exercises, government spending is set to equal $20 \%$ of total output.

Figure $5 A$ below illustrates the time path of optimal capital income taxes for the case with product market interventions. The solid blue line depicts 2021 reform whereas the red line with diamonds depicts 1983 reform. If the government reforms the tax system in year 2021, the optimal tax rate on capital starts roughly from a level of $26 \%$, increases over time, 
and converges to its long-run steady state level of about $28 \%$. If the tax reform is carried out in 1983, the optimal capital tax rate starts from a smaller level of $8 \%$ and over time it converges to a long-run steady state level of $27 \%$.

These quantitative findings have three key implications. First, and foremost, in both reforms, the optimal tax rate on capital income is positive and large both in the short run and in the long run. Recall from the discussion in Section 3.1 that taxes on capital income are desirable in our environment because they act as indirect and direct taxes on profit income. That the optimal capital tax rate is significantly positive implies that the indirect and direct tax on profits channels are quantitatively significant. Second, the optimal capital tax rate in the 1983 reform start low and rise with time following the time path of the profit share. This is expected since, as (23) and (24) reveal, the strength of both the indirect and the direct profit tax channels depend on the share of profits in national income. Third, the optimal capital tax rates in the 2021 reform are larger than those in the 1983 reform both along the transition and in the long run even though the evolution of the profit shares are identical in the two cases. This is because the government has to finance a higher initial debt at the time of the 2021 reform. A glance at the long-run tax formula given by (35) shows that higher revenue requirement for the government imply higher optimal capital taxes via the term $\chi^{*}$, which represents the relative social value of public funds. One way to interpret this finding is that four decades of inefficient tax policy since the early 1980's lead to higher optimal taxes in the 2021 reform.

Figure $5 B$ shows that optimal labor income taxes are fairly smooth around $32 \%$ and $34 \%$ in the 1982 and 2020 reforms, respectively. This is in line with the standard labor tax smoothing results of Barro (1979) and Lucas and Stokey (1983). Comparison of the optimal labor income taxes across the two reforms shows that postponing the reform leads to higher taxes in terms of labor taxes as well. 
A. Optimal Capital Income Taxes

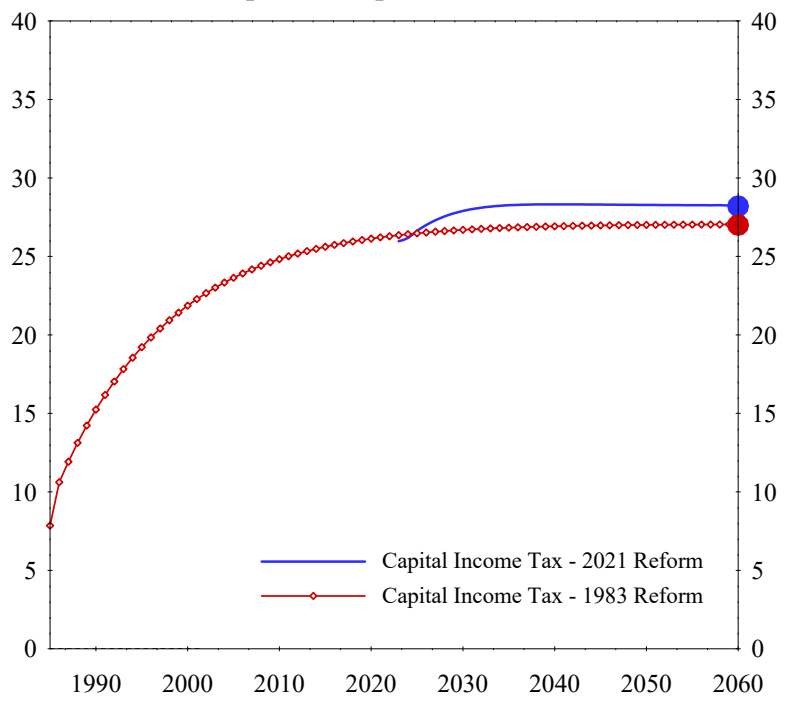

B. Optimal Labor Income Taxes

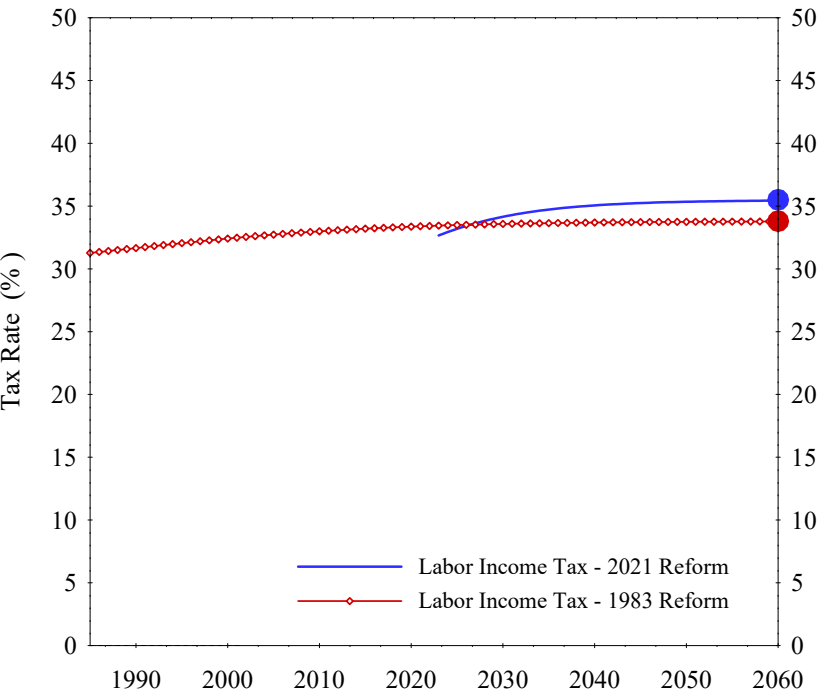

Figure 5: Optimal Tax Rates - Baseline Case

This figure depicts the time series of the optimal capital income tax rates (a) and the optimal labor income tax rates (b) for the baseline implementation with product market subsidies.

\subsection{Optimal Taxes without Product Market Policies}

Figure $6 \mathrm{~A}$ below illustrates the time path of optimal capital income taxes for the implementation without product market interventions. In the 2021 reform, the optimal tax rate on capital income is around its long-run level of 9.6\% throughout the period of interest. In the 1983 reform, the optimal capital income tax rate starts low again and then increases to a long-run steady state level of $8.4 \%$. Notice that optimal capital tax rates are significantly lower than those in the case with product market interventions. A comparison of the steady-state optimal capital tax formula in the absence of product market policies, given by (28), with the formula for the case with product market policies, given by (35), displays the reason. In the former case, there is an additional term, $-\frac{1}{\varepsilon} F_{k}^{*}$, that calls for a subsidy on capital income. This term is absent in the implementation with product market policies since in this case monopolistic distortion are already dealt with at the firm level where they originate. 
Figure $6 B$ shows that, in line with standard labor tax smoothing motivations, the optimal tax rate on labor income seems to be roughly constant at around $23 \%$ for both Ramsey problems, with only a slight exception in the 1980s during when optimal labor taxes are slightly above their long-run equilibrium level.

A. Optimal Capital Income Taxes

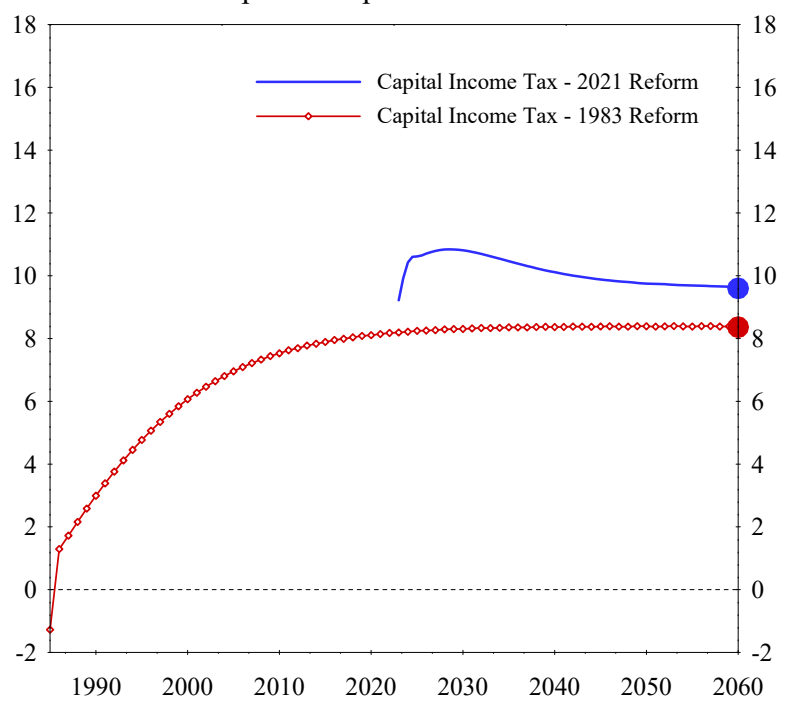

B. Optimal Labor Income Taxes

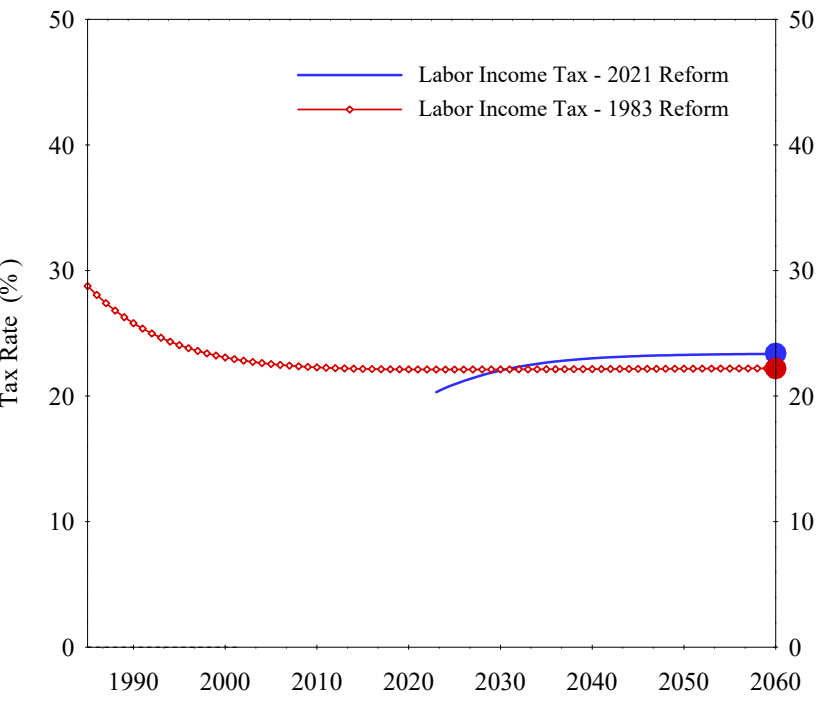

Figure 6: Optimal Tax Rates without Product Market Interventions

This figure depicts the time series of the optimal capital income tax rates (a) and the optimal labor income tax rates (b) for the implementation in which government is not allowed to use product market subsidies.

\section{Optimal Taxation in an Inefficient Economy}

The optimal tax analysis so far has been carried out under the assumption that the government is able to fully correct monopolistic distortions that slow down capital accumulation and cause underemployment, be it via subsidizing capital and labor income or via product market policies. However, in reality structural problems such as product market distortions might be hard to solve for a variety of reasons. ${ }^{21}$ A natural question then is: to what extent

\footnotetext{
${ }^{21}$ One such reason, for instance, might be that the degree of monopolistic distortions are heterogenous across firms and depend on unobservable firm characteristics. In such a world, it would be impossible to fully correct monopolistic distortions as the magnitude of Pigouvian corrections would depend on charac-
} 
do our conclusions about taxation of capital income change when the government is not able to correct monopolistic distortions? This section addresses this question by analyzing optimal Ramsey taxation in a world with inefficiently low levels of capital accumulation and employment resulting from monopolistic distortions. To do so, we modify the Ramsey problem as follows.

Ramsey problem. Given $\left(k_{1}, b_{1}\right)$, initial policies $\tau_{\pi, 1}=\tau_{k, 1}=\bar{\tau}_{k, 1}$, a sequence $\left\{\tilde{\pi}_{t}\right\}_{t=1}^{\infty}$ and a sequence of government spending $\left\{g_{t}\right\}_{t=1}^{\infty}$, government chooses allocation $(c, k, l)$ to solve the following problem:

$$
\begin{gathered}
\max _{c, k, l} \sum_{t=1}^{\infty} \beta^{t-1} u\left(c_{t}, l_{t}\right) \\
\text { s.t. } \\
c_{t}+q_{t} k_{t+1}+g_{t} \leq\left(1-\frac{1}{\varepsilon_{t}}\right) F_{t}\left(k_{t}, l_{t}\right)+\tilde{\pi}_{t}+(1-\delta) q_{t} k_{t}, \quad \text { for all } t, \\
\sum_{t=1}^{\infty} \beta^{t-1}\left(u_{c, t} c_{t}+u_{l, t} l_{t}\right)=\sum_{t=1}^{\infty} \beta^{t-1} u_{c, t}\left(1-\tau_{\pi, t}\right) \pi_{t}+u_{c, 1}\left(\bar{r}_{1} k_{1}+b_{1}\right),
\end{gathered}
$$

where $\pi_{t}=\frac{1}{\varepsilon_{t}} F_{t}\left(k_{t}, l_{t}\right)$ and $\tau_{\pi, t}$ is given by $(20)$, and in each period $t$, exogenously given profit income coincides with the profit income that the Ramsey problem generates: $\tilde{\pi}_{t}=\frac{1}{\varepsilon_{t}} F_{t}\left(k_{t}, l_{t}\right)$.

To understand this problem, observe that in the equilibrium of our growth model with distortions, the private marginal returns to capital and labor faced by the intermediate goods producers are $\left(1-\frac{1}{\varepsilon_{t}}\right) F_{k, t}$ and $\left(1-\frac{1}{\varepsilon_{t}}\right) F_{l, t}$, respectively. The social marginal returns, which can be observed from the Ramsey planning problem given by (32) (or 21), on the other hand, equal $F_{k, t}$ and $F_{l, t}$. Technically, it is these wedges between the private and the social returns that make it optimal to introduce corrective subsidies in Section 4 (or a motive to subsidize capital and labor income in Section 3.2). The planning problem (45) above modifies the planning problem (32) to ensure that the marginal returns to capital and labor perceived by teristics privately observed by firms. See Boar and Midrigan (2020) for an analysis of optimal regulation of monopolistic distortions in the presence of informational frictions. 
the Ramsey planner are equal to the private returns firms face in equilibrium. This is achieved by revising the resource constraint as in (45) by writing output as a summation of two parts: $\left(1-\frac{1}{\varepsilon_{t}}\right) F\left(k_{t}, l_{t}\right)$ and $\tilde{\pi}_{t}$. The first part ensures that the Ramsey planner perceives the same returns as the private agents. By setting the second part to $\tilde{\pi}_{t}=\frac{1}{\varepsilon_{t}} F\left(k_{t}, l_{t}\right)$, we ensure that, as in the market equilibruim, total output is given by $F_{t}\left(k_{t}, l_{t}\right)$. This formulation guarantees that monopolistic distortions are not corrected in the solution to the Ramsey problem (45).

Steady-state optimal tax formulas. Plugging the first-order optimality conditions of the above Ramsey problem for consumption, labor and capital in the definition of tax rates given by (26) and (27) at the steady state, we obtain the following optimal tax formulas.

Proposition 7. The long-run optimal tax rate on capital and labor income are given by

$$
\tau_{k}^{*}=\frac{1}{\left(1-\frac{1}{\varepsilon}\right) F_{k}^{*}-\delta q} \chi^{*}\left[\frac{\partial \pi^{*}}{\partial k}\left(1-\tau_{\pi}^{*}\right)+\frac{\partial\left(1-\tau_{\pi}^{*}\right)}{\partial k} \pi^{*}\right]
$$

and

$$
\tau_{l}^{*}=1-\frac{1+\lambda^{*}\left(1+\frac{u_{c c}^{*} c^{*}}{u_{c}^{*}}\right)}{1+\lambda^{*}\left(1+\frac{u_{l l}^{*} l^{*}}{u_{l}^{*}}\right)}\left(1-\chi^{*} \frac{1}{F_{l}^{*}\left(1-\frac{1}{\varepsilon}\right)}\left(\frac{\partial \pi^{*}}{\partial l}\left(1-\tau_{\pi}^{*}\right)+\frac{\partial\left(1-\tau_{\pi}^{*}\right)}{\partial l} \pi^{*}\right)\right)
$$

Proof. Relegated to Appendix A.6.

Notice that the optimal capital tax formula given by (46) is quite similar to the optimal capital tax formula for the benchmark case in which distortions are corrected via product market policies given by (35). Specifically, the capital subsidy term, $-\frac{1}{\varepsilon} F_{k}^{*}$, which is present in the optimal capital tax formula in the case without product market distortions, (28), is absent from both the optimal tax formulas (35) and (46). The reason for why this term is absent differs across the two environments, however. While product market interventions eliminate the distortions and, therefore, the need for a subsidy on capital income in (35), the assumption that the Ramsey planner cannot correct monopolistic distortions imply that 
there is no motive for a subsidy in (46).

It is only the first terms, $\frac{1}{\left(1-\frac{1}{\varepsilon}\right) F_{k}^{*}-\delta q}$ vs. $\frac{1}{F_{k}^{*}-\delta q}$, that differ across the capital tax formulas (35) and (46). This reflects the fact that the interest rate is inefficiently low in the inefficient economy due to the low investment demand arising from monopolistic distortions, and implies that, ceteris paribus, the tax rate on capital income should be higher in the inefficient economy since the capital tax base is smaller. A similar comparison applies to the optimal labor income taxes in the two cases.

We can also provide a lower bound on optimal capital income taxes in this case.

Proposition 8. Suppose $u(c, l)=\frac{c^{1-\sigma}}{1-\sigma}-v(l)$, where $v^{\prime}, v^{\prime \prime}>0$, and $F(k, l)=A k^{\alpha} l^{1-\alpha}$. The optimal long-run tax rate on capital income satisfies:

$$
\tau_{k}^{*}>\frac{1}{1+\left(\frac{1}{\lambda^{*}}+1-\sigma\right)(\varepsilon-1) \alpha} .
$$

Proof. Relegated to Appendix A.7.

A comparison of the lower bound given by Proposition 8 with the lower bound given in Proposition 5 reveals that the former is larger for an identical value of social value of public funds. This is intuitive since the interest rate, and hence, the capital income tax base, is lower in the inefficient economy, which overall calls for higher optimal taxes when tax revenue needs are identical.

\subsection{Quantitative Analysis}

Figure 7 below displays the optimal capital and labor income tax series under the assumption that monopolistic distortions are not corrected. In the 2021 reform, the optimal tax rate on capital turns out to be positive and roughly constant at around its long-run equilibrium level of $20.8 \%$ in all calendar years. In the 1983 reform, the optimal capital tax rate starts at a small but positive level, increases over time, and converges to its long-run level of $22.3 \%$. 
The optimal labor income taxes are smooth and roughly constant over the periods of interest in both reforms.

A. Optimal Capital Income Taxes

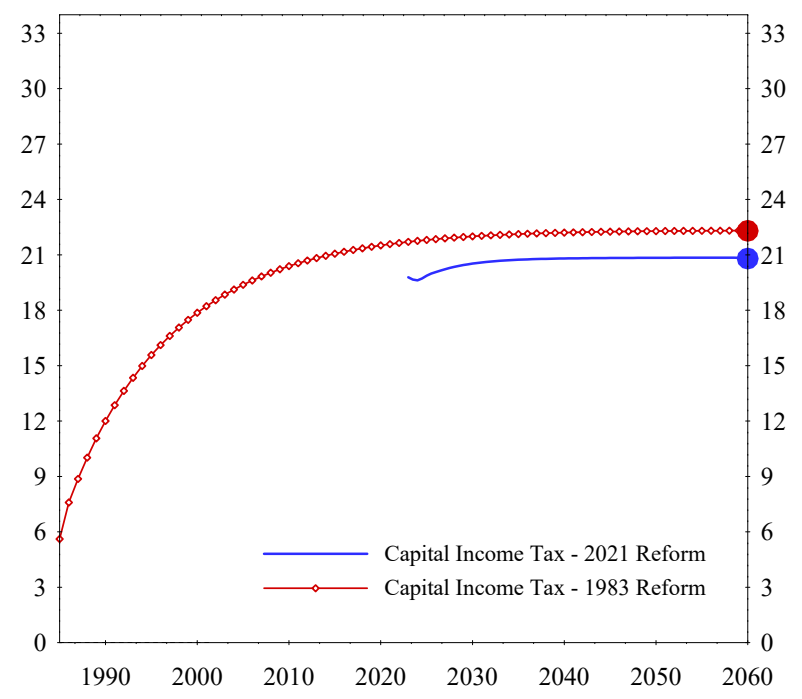

B. Optimal Labor Income Taxes

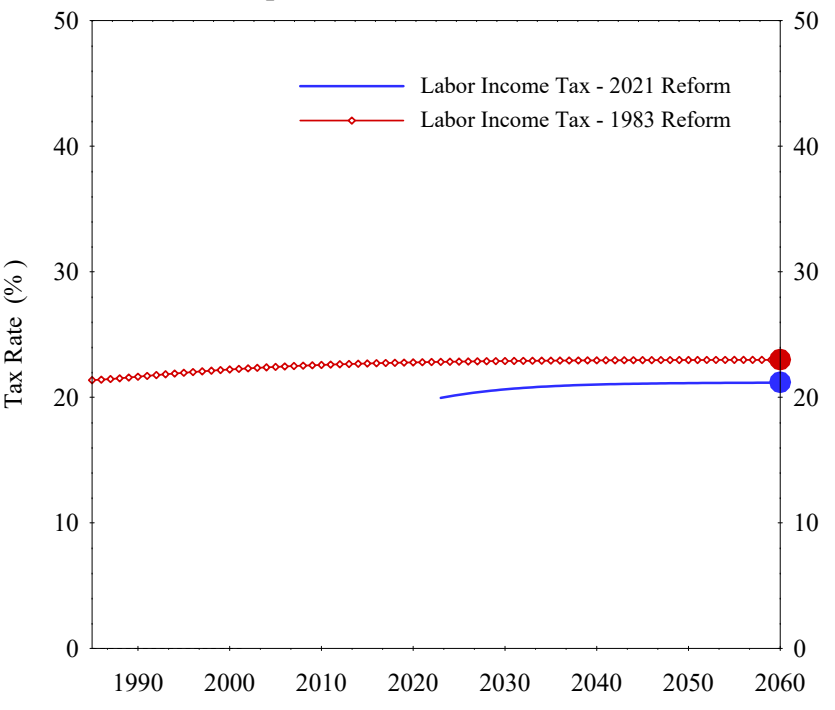

Figure 7: Optimal Tax Rates in the Inefficient Economy

This figure depicts the time series of the optimal capital income tax rates (a) and the optimal labor income tax rates (b) for the economy in which government cannot correct monopolistic distortions.

The main message to take away from Figure 7 is that the optimal capital taxes are still positive and significant when product market distortions are not corrected. Comparing Figure 5 and Figure 7, we observe that the optimal taxes in the inefficient economy are lower compared to the case where monopolistic distortions are corrected with product market subsidies. This may be somewhat surprising given that the tax base in the inefficient economy, $\frac{1}{\left(1-\frac{1}{\varepsilon}\right) F_{k}^{*}-\delta q}$, is smaller than the tax base in the economy with corrective subsidies, $\frac{1}{F_{k}^{*}-\delta q}$, which implies that, all else equal, the tax rate should be higher in the inefficient economy. The opposite is true because all else is not equal across the two cases: namely, the relative social value of public funds, $\chi^{*}$, is smaller in the inefficient economy. Recall that $\chi^{*}$ represents the value of an additional dollar in government's pocket relative to the value of an additional dollar to the society. This value is lower for the inefficient economy because, while the value of an additional dollar for the government is the same in the two cases, the value 
of an additional dollar to society is higher due to the economy being inefficiently smaller. ${ }^{22}$

\section{Optimal Taxation with Exogenous Profit Taxes}

The optimal tax analysis so far assumed that the tax rate on capital and profit income has to be the same, perhaps because it is hard to separate capital and profit income. In this section, we derive optimal tax formulas for the case where profit income is taxed at a different rate than capital income. If we allow the government to choose the tax rate on profit income freely, it would choose it to be $100 \%$ since, as previously argued, tax on profits is a lump-sum tax in our environment. In reality, however, taxing profit income completely away may not be desirable or feasible for reasons that are not captured by our model. For this reason, we are going to set an exogenous upper limit to the profit tax rate that the government can set. We maintain the assumption that the government uses product market policies to correct monopolistic distortions.

Ramsey problem. Given $\left(k_{1}, b_{1}\right)$, initial capital levy $\tau_{k, 1}=\bar{\tau}_{k, 1}$, the sequence of profit taxes $\left\{\bar{\tau}_{\pi, t}\right\}_{t=1}^{\infty}$, and a sequence of government spending $\left\{g_{t}\right\}_{t=1}^{\infty}$, government chooses allocation $(c, k, l)$ to solve the following problem:

$$
\begin{gathered}
\max _{c, k, l} \sum_{t=1}^{\infty} \beta^{t-1} u\left(c_{t}, l_{t}\right) \\
\text { s.t. } \\
c_{t}+q_{t} k_{t+1} \leq F_{t}\left(k_{t}, l_{t}\right)+(1-\delta) q_{t} k_{t}, \quad \text { for all } t \\
\sum_{t=1}^{\infty} \beta^{t-1}\left(u_{c, t} c_{t}+u_{l, t} l_{t}\right)=\sum_{t=1}^{\infty} \beta^{t-1} u_{c, t}\left(1-\bar{\tau}_{\pi, t}\right) \pi_{t}+u_{c, 1}\left(\bar{r}_{1} k_{1}+b_{1}\right),
\end{gathered}
$$

\footnotetext{
${ }^{22}$ Technically, the social value of an additional dollar of government revenue is measured by the tightness of the implementability constraint in the solution, and the implementability constraints are identical across the two Ramsey problems (32) and (45). The value of an additional dollar to the society, on the other hand, is measured by the tightness of the feasibility constraint, and the feasibility constraint in the Ramsey problem (45) displays an inferior production function compared to the former Ramsey problem given by (32).
} 
where $\pi_{t}=\frac{1}{\varepsilon_{t}} F_{t}\left(k_{t}, l_{t}\right)$.

Notice that the key difference of this problem relative to the Ramsey problem given by (32) is that here profit tax is exogenously given. As a result, the problem does not have constraint (31) which defines the profit tax rate.

Steady-state optimal tax formulas. Plugging the first-order optimality conditions of the above Ramsey problem for consumption, labor and capital in the definition of tax rates given by (26) and (27) at the steady state, we obtain the following optimal tax formulas.

Proposition 9. The optimal tax rate on capital and labor income in all $t \geq 2$ are given by

$$
\tau_{k}^{*}=\frac{1}{F_{k}^{*}-\delta q} \chi^{*} \frac{\partial \pi^{*}}{\partial k}\left(1-\bar{\tau}_{\pi}\right)
$$

and

$$
\tau_{l}^{*}=1-\frac{1+\lambda^{*}\left(1+\frac{u_{c c}^{*} c^{*}}{u_{c}^{*}}\right)}{1+\lambda^{*}\left(1+\frac{u_{l l}^{*} l^{*}}{u_{l}^{*}}\right)}\left(1-\chi^{*} \frac{1}{F_{l}^{*}} \frac{\partial \pi^{*}}{\partial l}\left(1-\bar{\tau}_{\pi}\right)\right)
$$

Proof. Relegated to Appendix A.8.

The main difference between the optimal capital tax formula given by (50) and the optimal tax formula in the benchmark case with uniform tax rate on capital and profit income given by (35) is that in the former the direct taxation of profits term is absent. This is intuitive: a rise in capital income tax does not act as a rise in profit income tax since the two are separate. The only way in which taxing capital acts as a tax on profit income is through the indirect tax channel, the magnitude of which is now controlled by the exogenous tax rate on profit income, $\bar{\tau}_{\pi}$.

\subsection{Quantitative Analysis}

In the case with exogenously fixed profit income taxes, the sequence of tax rates on profit income is an additional parameter in the Ramsey planning problem. Following the calibration 
of the benchmark model in Section 5.2, we set the profit income tax sequence to the sequence of status-quo capital income taxes. ${ }^{23}$

Figure $8 A$ illustrates the time-path of optimal capital income taxes. We find that in the 2021 reform, the optimal tax rate on capital starts roughly from a level of $7 \%$, increases over time and converges to a level of $8.7 \%$ in the long run. In the 1983 reform, the tax rate is again increasing through time converging to a long-run level of $6.7 \%$. The first takeaway message from the figure is that the optimal capital taxes are positive and significant under both reforms. Second, the optimal capital tax rates are smaller than the ones in the benchmark analysis where capital and profit income are taxed at the same rate, given by Figure $5 A$. This is expected since the direct tax on profit income term that shows up in the the optimal capital tax formula in the benchmark analysis (35) is absent in the optimal capital tax formula in the current case (50). ${ }^{24}$

\footnotetext{
${ }^{23}$ Recall that, in the benchmark calibration, the profit tax rate $\tau_{\pi}$ decreases from $40 \%$ to $30 \%$ following the observed capital income tax series. As a sensitivity analysis, we also consider an alternative calibration of the profit tax sequence in which $\tau_{\pi}$ is set to equal the observed tax rate on distributions (see McGrattan and Prescott 2010), decreasing from a level of $40 \%$ to $15 \%$ over the period of interest. We find that optimal capital income taxes are again positive and actually somewhat higher than the ones implied by the benchmark calibration. The details of this alternative calibration procedure and the optimal tax results are given in Appendix B.

${ }^{24}$ Looking at Figure $8 A$, one may wonder as to why the optimal capital tax rate is negative in the first few periods following the 1983 reform. To see this, recall that the Ramsey planner would like to minimize the net-present value of after-tax profits that appears on the right-hand -side of the implementability constraint in (49). A subsidy on period $t$ capital income increases savings into period $t$, which increases consumption and hence decreases the equilibrium price of consumption in that period. Since period $t$ profits accrue in period $t$ prices, this decreases present value of period $t$ profits, giving government an indirect way of taxing them. This introduces a motive to subsidize period $t$ capital income. The exact same logic tells us that there is a force that is calling for a tax on period $t$ capital income. Intuitively, taxing capital income in period $t$ decreases saving into period $t$. As a result, period $t-1$ consumption increases, decreasing the price and hence the present value of period $t-1$ untaxed profits. The magnitude of these forces are proportional to the amount of after-tax profit income in each period. Since the profit tax rate is declining over time in our calibration, the subsidy motivation dominates the tax motivation and we get subsidies on capital income to be optimal early on. The tax on capital income turns positive after a while because the profit share is becomes large and the aforementioned price effects of taxing capital become too small relative to the indirect profit tax revenue benefit of capital taxation. We do not get negative taxes to be optimal even early on in the baseline case with uniform tax on capital and profit income because in that case the presence of the additional direct profit tax revenue effect of capital income taxation dominates the price effects from the start of the reform. Finally, the price effects do not appear in the steady-state formulas because the subsidy and tax forces coming through price effects exactly cancel out in a steady state.
} 
A. Optimal Capital Income Taxes

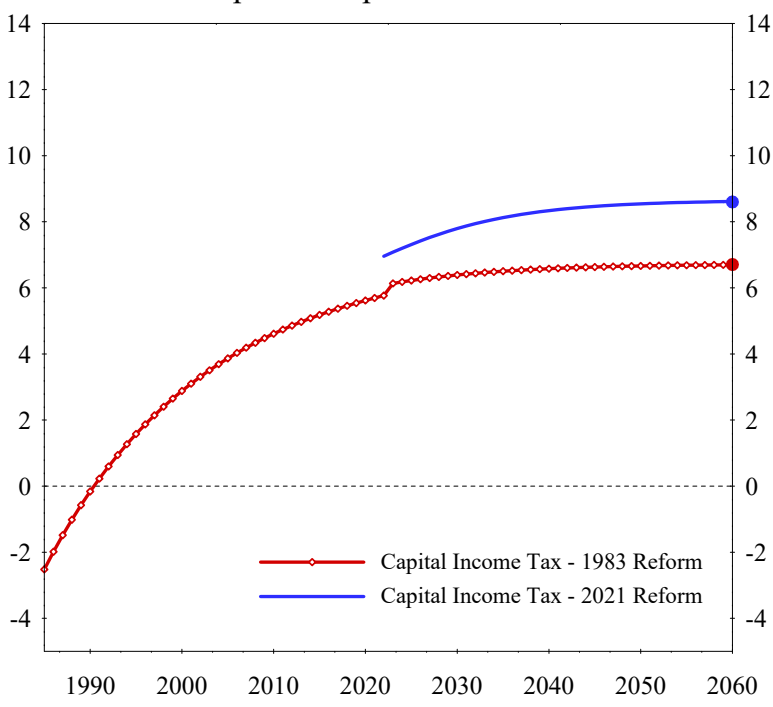

B. Optimal Labor Income Taxes

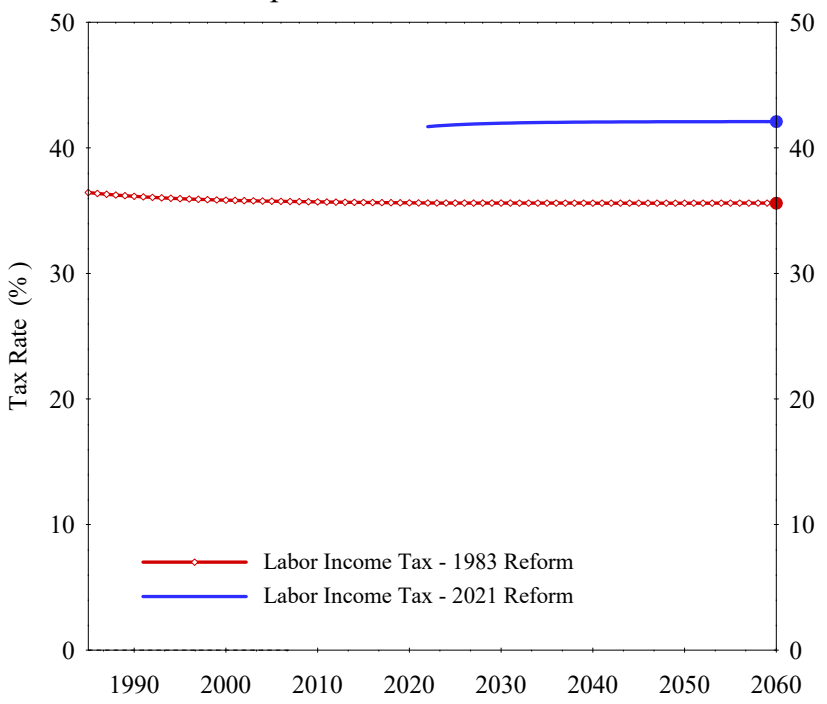

Figure 8: Optimal Tax Rates under Exogenous Profit Taxes

This figure depicts the time series of the optimal capital income tax rates (a) and the optimal labor income tax rates (b) for the case in which government can differentiate between capital and profit taxes and the latter is exogenously fixed.

\section{Conclusion}

Numerous recent studies have documented that the labor's share in national income, which has been quite stable until the early 1980's, has been declining at a considerable rate since then. In this paper, we analyze the implications of this decline on the optimal capital and labor income taxation from the perspective of a government that needs to finance spending. Our main qualitative finding is that the optimal tax implications of the decline in the labor share depend on the mechanism responsible for it. In particular, if the labor share declines because of rising market power or other mechanisms that raise the share of profits in national income, then the decline in the labor share should optimally be accompanied with a rise in capital income taxes. If, on the other hand, the labor share declines because of a rise in capital share, then it has no bearing on optimal capital income taxation. In our baseline calibration, we find that the optimal tax rate on capital income rises about 8-25\% from the early 1980's to 2021 depending on institutional arrangements regarding taxation of profit income. 


\section{References}

Acemoglu, D., A. Manera, and P. Restrepo (2020): "Does the US Tax Code Favor Automation?," NBER Working Papers 27052, National Bureau of Economic Research, Inc.

Acemoglu, D., And P. Restrepo (2019): "Automation and New Tasks: How Technology Displaces and Reinstates Labor," Journal of Economic Perspectives, 33(2), 3-30.

Atkeson, A., And A. Burstein (2019): "Aggregate Implications of Innovation Policy," Journal of Political Economy, 127(6), 2625-2683.

AtKeson, A., And P. J. Kehoe (2005): "Modeling and Measuring Organization Capital," Journal of Political Economy, 113(5), 1026-1053.

Autor, D., D. Dorn, L. F. Katz, C. Patterson, and J. V. Reenen (2017): "Concentrating on the Fall of the Labor Share," American Economic Review, 107(5), 180-185.

Barkai, S. (2019): "Declining Capital and Income Shares," Journal of Finance, Forthcoming.

Barkai, S., and S. Benzell (2018): "70 Years of US Corporate Profits," Working Paper 22, Stigler Center for the Study of the Economy and the State.

Barro, R. J. (1979): "On the Determination of the Public Debt," Journal of Political Economy, 87(5), 940-971.

Boar, C., ANd V. Midrigan (2020): "Markups and Inequality," Discussion paper.

Caballero, R. J., E. Farhi, and P.-O. Gourinchas (2017): "Rents, Technical Change, and Risk Premia Accounting for Secular Trends in Interest Rates, Returns on Capital, Earning Yields, and Factor Shares," American Economic Review, 107(5), 614-620. 
Chamley, C. (1986): "Optimal Taxation of Capital Income in General Equilibrium with Infinite Lives," Econometrica, 54(3), 607-622.

Chari, V., And P. J. Kehoe (1999): "Optimal fiscal and monetary policy," in Handbook of Macroeconomics, ed. by J. B. Taylor, and M. Woodford, vol. 1 of Handbook of Macroeconomics, chap. 26, pp. 1671-1745. Elsevier.

Chari, V., J. P. Nicolini, and P. Teles (2020): "Optimal capital taxation revisited," Journal of Monetary Economics, 116, 147-165.

Chetty, R., A. Guren, D. Manoli, and A. Weber (2011): "Are Micro and Macro Labor Supply Elasticities Consistent? A Review of Evidence on the Intensive and Extensive Margins," American Economic Review, 101(3), 471-475.

Conesa, J. C., S. Kitao, and D. Krueger (2009): "Taxing Capital? Not a Bad Idea after All!," American Economic Review, 99(1), 25-48.

Costinot, A., And I. Werning (2018): "Robots, Trade, and Luddism: A Sufficient Statistic Approach to Optimal Technology Regulation," NBER Working Papers 25103, National Bureau of Economic Research, Inc.

Coto-Martínez, J., C. Garriga, and F. SÁnchez-Losada (2007): "Optimal Taxation with Imperfect Competition and Aggregate Returns to Specialization," Journal of the European Economic Association, 5(6), 1269-1299.

Dasgupta, P., And J. E. Stiglitz (1971): "Differential Taxation, Public Goods, and Economic Efficiency," Review of Economic Studies, 38(2), 151-174.

De Loecker, J., J. Eeckhout, And G. Unger (2019): "The Rise of Market Power and the Macroeconomic Implications," Quarterly Journal of Economics, Forthcoming.

Diamond, P. A., And J. A. Mirrlees (1971): "Optimal Taxation and Public Production I: Production Efficiency," American Economic Review, 61(1), 8-27. 
DomeiJ, D., And J. Heathcote (2004): "On the Distributional Effects of Reducing Capital Taxes," International Economic Review, 45(2), 523-554.

Edmond, C., V. Midrigan, and D. Y. Xu (2018): "How Costly Are Markups?," NBER Working Papers 24800, National Bureau of Economic Research, Inc.

Eggertsson, G. B., J. A. Robbins, and E. G. Wold (2018): "Kaldor and Piketty?s Facts: The Rise of Monopoly Power in the United States," NBER Working Papers 24287, National Bureau of Economic Research, Inc.

Elsby, M., B. Hobijn, and A. Sahin (2013): "The Decline of the U.S. Labor Share," Brookings Papers on Economic Activity, 44(2 (Fall)), 1-63.

FARHI, E., AND F. GourIo (2018): "Accounting for Macro-Finance Trends: Market Power, Intangibles, and Risk Premia," Brookings Papers on Economic Activity, 49(2 (Fall)), 147250.

Guerreiro, J., S. Rebelo, and P. Teles (2019): "What is the Optimal Immigration Policy? Migration, Jobs and Welfare," NBER Working Papers 26154, National Bureau of Economic Research, Inc.

Guo, J.-T., And K. J. LANsing (1999): "Optimal taxation of capital income with imperfectly competitive product markets," Journal of Economic Dynamics and Control, 23(7), 967-995.

Jones, L. E., R. E. Manuelli, and P. E. Rossi (1997): "On the Optimal Taxation of Capital Income," Journal of Economic Theory, 73(1), 93-117.

JudD, K. L. (1985): "Redistributive Taxation in a Simple Perfect Foresight Model," Journal of Public Economics, 28(1), 59-83.

(2002): "Capital-Income Taxation with Imperfect Competition," American Economic Review, 92(2), 417-421. 
Karabarbounis, L., and B. Neiman (2014): "The Global Decline of the Labor Share," The Quarterly Journal of Economics, 129(1), 61-103.

(2018): "Accounting for Factorless Income," NBER Working Papers 24404, National Bureau of Economic Research, Inc.

Lucas, R. J., And N. L. Stokey (1983): "Optimal fiscal and monetary policy in an economy without capital," Journal of Monetary Economics, 12(1), 55-93.

McGrattan, E. R., and E. C. Prescott (2010): "Technology Capital and the US Current Account," American Economic Review, 100(4), 1493-1522.

Philippon, T. (2019): The Great Reversal: How America Gave Up on Free Markets, Economics Books. The Belknap Press of Harvard University.

Ramsey, F. P. (1928): "A Mathematical Theory of Savings," The Economic Journal, $38(152), 543-559$.

Slavik, C., And H. Yazici (2014): "On the Consequences of Eliminating Capital Tax Differentials," Working paper.

Straub, L., And I. Werning (2020): "Positive Long-Run Capital Taxation: ChamleyJudd Revisited," American Economic Review, 110(1), 86-119.

Thuemmel, U. (2018): "Optimal Taxation of Robots," CESifo Working Paper Series 7317, CESifo Group Munich. 


\section{Appendix}

\section{A Proofs}

\section{A.1 Proof of Proposition 1}

Proof. We first show that equilibrium allocation satisfies (18), (19), and (20). The fact that equilibrium allocation satisfies (18) follows from the fact that equilibrium allocation satisfies (11) and (17) with equality.

To see (19), first notice that if we plug (13) into (11) and use the transversality condition $\lim _{t \rightarrow \infty} p_{t} q_{t} k_{t+1}=0$, we achieve

$$
\sum_{t=1}^{\infty} p_{t} c_{t}=\sum_{t=1}^{\infty} p_{t}\left(w_{t} l_{t}\left(1-\tau_{l, t}\right)+\pi_{t}\left(1-\tau_{\pi, t}\right)\right)+p_{1} b_{1}
$$

Normalizing $p_{1}=1$, plugging in (12) and (14) into (52) and, multiplying both sides by $u_{c, 1}$, we prove that the allocation satisfies (19).

When we combine the first-order optimality conditions of the consumer, (12) and (13), with the equilibrium rental rate of capital given by (7), we see that in equilibrium:

$$
u_{c, t-1} q_{t-1}=\beta u_{c, t}\left[q_{t}+\left(\left(1-\frac{1}{\varepsilon_{t}}\right) F_{k, t}-\delta q_{t}\right)\left(1-\tau_{k, t}\right)\right]
$$

Deriving $1-\tau_{k, t}$ from (53) and recalling $\tau_{\pi, t}=\tau_{k, t}$ proves that equilibrium allocation satisfies $(20)$.

Now, we prove the other direction. Suppose an allocation together with initial policies satisfies (18), (19), and (20). We will show that this allocation, with properly constructed prices and taxes, constitutes a tax-distorted equilibrium. First, use (7), (8), and $\pi_{t}=\frac{1}{\varepsilon_{t}} y_{t}$ to construct factor prices and profit income every period. Normalize $p_{1}=1$ and use (12) to set $p_{t}$. Use (53) to construct capital (and profit) income taxes for periods $t \geq 2$ and and (14) 
to construct labor income taxes for periods $t \geq 1$. Given this constructions, the allocation satisfies consumer and firm optimality conditions. Using the constructed prices and taxes and transversality condition in (19), we obtain that the allocation satisfies consumer budget constraint (11). Combining (11) with the resource constraint (18) gives the government budget constraint (17), which completes the proof.

\section{A.2 First-order optimality conditions of Ramsey Problem (21)}

Although the first-order optimality conditions for capital and labor are provided in the main text, we report them here again for completeness. Letting $\mu_{t}$ and $\lambda$ be LaGrange multipliers on period $t$ feasibility constraint and implementability constraint, the full set of first-order conditions are as follows. For $t \geq 2$ :

$$
\begin{gathered}
\left(k_{t}\right):-\mu_{t-1}^{*} q_{t-1}+\mu_{t}^{*}\left(F_{k, t}^{*}+(1-\delta) q_{t}\right) \\
-\lambda^{*} \beta^{t-1} u_{c, t}^{*}\left[\left(1-\tau_{\pi, t}^{*}\right) \frac{\partial \pi_{t}^{*}}{\partial k_{t}}+\frac{\partial\left(1-\tau_{\pi, t}^{*}\right)}{\partial k_{t}} \pi_{t}^{*}\right]=0 \\
\left(l_{t}\right): \beta^{t-1} u_{l, t}^{*}+\lambda^{*} \beta^{t-1}\left[u_{l l, t}^{*} l_{t}+u_{l, t}^{*}\right] \\
-\lambda^{*} \beta^{t-1} u_{c, t}^{*}\left[\left(1-\tau_{\pi, t}^{*}\right) \frac{\partial \pi_{t}^{*}}{\partial l_{t}}+\frac{\partial\left(1-\tau_{\pi, t}^{*}\right)}{\partial l_{t}} \pi_{t}^{*}\right]+\mu_{t}^{*} F_{l, t}^{*}=0, \\
\left(c_{t}\right): \beta^{t-1} u_{c, t}^{*}+\lambda^{*} \beta^{t-1}\left[u_{c c, t}^{*} c_{t}^{*}+u_{c, t}^{*}\right]-\lambda^{*} \beta^{t-1} u_{c c, t}^{*}\left(1-\tau_{\pi, t}^{*}\right) \pi_{t}^{*} \\
-\lambda^{*} \beta^{t-1}\left[u_{c, t}^{*} \frac{\partial\left(1-\tau_{\pi, t}^{*}\right)}{\partial c_{t}} \pi_{t}^{*}+u_{c, t+1}^{*} \frac{\partial\left(1-\tau_{\pi, t+1}^{*}\right)}{\partial c_{t}} \pi_{t+1}^{*}\right]-\mu_{t}^{*}=0 .
\end{gathered}
$$


The first-order optimality conditions for consumption and labor are different for $t=1$ :

$$
\begin{array}{ll}
\left(c_{1}\right): & u_{c, 1}^{*}+\lambda^{*}\left[u_{c c, 1}^{*} c_{1}^{*}+u_{c, 1}^{*}-u_{c c, 1}^{*}\left(1-\tau_{\pi, 1}^{*}\right) \pi_{1}^{*}-u_{c c, 2}^{*} \frac{\partial\left(1-\tau_{\pi, 2}^{*}\right)}{\partial c_{1}} \pi_{2}^{*}-u_{c c, 1} A_{1}\right]-\mu_{1}^{*}=0, \\
\left(l_{1}\right): & u_{l, 1}^{*}+\lambda^{*}\left[u_{l l, 1}^{*} l_{1}^{*}+u_{l, 1}^{*}-u_{c, 1}^{*}\left(1-\bar{\tau}_{\pi, 1}\right) \frac{\partial \pi_{1}^{*}}{\partial l_{1}}\right]+\mu_{1}^{*} F_{l, 1}^{*}=0,
\end{array}
$$

where $A_{1}=\bar{r}_{1} k_{1}+b_{1}$ is the real value of initial assets.

\section{A.3 Proof of Proposition 3}

Proof. We show that the allocation $\left\{c_{t}, k_{t+1}, l_{t}\right\}_{t=1}^{\infty}$ is consistent with firm optimization, consumer optimization, consumer budget constraint, and government budget constraint under appropriately defined prices and taxes. Market clearing is implied by the fact that this allocation is an equilibrium allocation without product market policies.

First, define taxes as follows. For all $t \geq 1$ :

$$
\begin{gathered}
1-\hat{\tau}_{k, t}=\frac{\left(1-\frac{1}{\varepsilon}\right) F_{k, t}-\delta q_{t}}{F_{k, t}-\delta q_{t}}\left(1-\tau_{k, t}\right), \\
1-\hat{\tau}_{l, t}=\left(1-\frac{1}{\varepsilon}\right)\left(1-\tau_{l, t}\right),
\end{gathered}
$$

and

$$
\hat{\tau}_{\pi, t}=\tau_{\pi, t} .
$$

Next, define prices as follows. For all $t \geq 1$ :

$$
\begin{gathered}
\hat{p}_{t}=p_{t}, \\
\hat{r}_{t}=F_{k, t}, \\
\hat{w}_{t}=F_{l, t} .
\end{gathered}
$$

First, let's consider the production side of the economy. The final good producer's prob- 
lem is unchanged, so it still implies the same demand function:

$$
y_{i, t}=y_{t} \xi_{i, t}^{-\varepsilon_{t}}
$$

Intermediate goods producers solve:

$$
\begin{gathered}
\hat{\pi}_{i, t}=\max _{\xi_{i, t}, y_{i, t}, k_{i, t}, l_{i, t}}\left(1+\hat{\tau}_{s, t}\right) \xi_{i, t} y_{i, t}-\hat{r}_{t} k_{i, t}-\hat{w}_{t} l_{i, t}-\hat{T}_{t} \\
\text { s.t. } \\
y_{i, t}=F_{t}\left(k_{i, t}, l_{i, t}\right)=\left(\alpha_{k, t}\left(A_{k, t} k_{i, t}\right)^{\rho}+\alpha_{l, t}\left(A_{l, t} l_{i, t}\right)^{\rho}\right)^{1 / \rho} .
\end{gathered}
$$

The intermediate good firm's problem can be solved in two steps. In the first step, for a given marginal cost of producing the good, $m_{i, t}$, the firm chooses price to maximize its profits:

$$
\max _{\xi_{i, t}}\left(1+\hat{\tau}_{s, t}\right) \xi_{i, t} y_{i, t}-m_{i, t} y_{i, t}-\hat{T}_{t} \quad \text { s.t. } \quad(63)
$$

The solution to this problem implies a constant markup over marginal cost

$$
\left(1+\hat{\tau}_{s, t}\right) \xi_{i, t}=m_{i, t} \frac{\varepsilon_{t}}{\varepsilon_{t}-1}
$$

In the symmetric equilibrium of the model, all varieties have the same production function and all intermediate goods firms make identical choices of inputs and prices. This implies $y_{i, t}=y_{t}$ and $\xi_{i, t}=1$ for all $i \in[0,1]$. We therefore have the optimal marginal cost of producing one more intermediate good equals for all firms $m_{i, t}=M_{t}=\frac{\varepsilon_{t}-1}{\varepsilon_{t}}\left(1+\hat{\tau}_{s, t}\right)=1$ under the specified sales subsidy.

In the second step, each firm chooses capital and labor to minimize the cost of producing intermediate good. The firms also make same input choices in the symmetric equilibrium, so we have $k_{i, t}=k_{t}$ and $l_{i, t}=l_{t}$. Marginal cost of producing one more unit using capital or 
labor at the optimum gives

$$
\frac{\hat{r}_{t}}{F_{k, t}}=\frac{\hat{w}_{t}}{F_{l, t}}=m_{t}=1
$$

which gives

$$
\hat{r}_{t}=F_{k, t}
$$

and

$$
\hat{w}_{t}=F_{l, t},
$$

in line with constructed factor prices in (61) and (62).

Using (66), we can calculate

$$
\hat{\pi}_{t}=\left(1+\hat{\tau}_{s, t}\right) \xi_{i, t} y_{i, t}-m_{i, t} y_{i, t}-\hat{T}_{t}=\frac{1}{\varepsilon_{t}} y_{t}=\pi_{t},
$$

verifying that profit income in the new equilibrium is the same as the profit income in the original equilibrium without product market policies.

Now, we turn to consumer side. We know that the allocation being part of an equilibrium without product market policies implies that for all $t \geq 1$ :

$$
u_{c, t} q_{t}=\beta u_{c, t+1}\left[q_{t+1}+\left(\left(1-\frac{1}{\varepsilon_{t}}\right) F_{k, t+1}-\delta q_{t+1}\right)\left(1-\tau_{k, t+1}\right)\right] .
$$

This condition, together with the definition of capital taxes given by (57) imply

$$
u_{c, t} q_{t}=\beta u_{c, t+1}\left[q_{t+1}+\left(F_{k, t+1}-\delta q_{t+1}\right)\left(1-\hat{\tau}_{k, t+1}\right)\right]
$$

Similarly, the allocation being part of an equilibrium without product market policies implies that for all $t \geq 1$ :

$$
-u_{l, t}=\left(1-\frac{1}{\varepsilon_{t}}\right) F_{l, t}\left(1-\tau_{l, t}\right) u_{c, t}
$$


This condition, together with the definition of labor taxes given by (58) imply

$$
-u_{l, t}=F_{l, t}\left(1-\hat{\tau}_{l, t}\right) u_{c, t}
$$

(73) and (75) together imply that the original allocation satisfies consumer's intertemporal and intratemporal optimality condition when he faces newly constructed prices and taxes, (60)-(62) and (57)-(59). Next we show that consumer's budget constraint holds with equality under the original allocation and newly constructed prices and taxes. Since the original allocation is an equilibrium allocation without product market policies, it satisfies consumer's budget constraint in the no product market policies environment. That is,

$$
\begin{aligned}
& \sum_{t=1}^{\infty} p_{t}\left(c_{t}+q_{t} k_{t+1}\right) \\
& =\sum_{t=1}^{\infty} p_{t}\left(w_{t} l_{t}\left(1-\tau_{l, t}\right)+\left[q_{t}+\left(r_{t}-q_{t} \delta\right)\left(1-\tau_{k, t}\right)\right] k_{t}+\pi_{t}\left(1-\tau_{\pi, t}\right)\right)+p_{1} b_{1} .
\end{aligned}
$$

Using (76), definitions of rental and wage rates (60)-(62), and the definition of taxes (57)(59), it follows that

$$
\begin{aligned}
& \sum_{t=1}^{\infty} \hat{p}_{t}\left(c_{t}+q_{t} k_{t+1}\right) \\
& =\sum_{t=1}^{\infty} \hat{p}_{t}\left(\hat{w}_{t} l_{t}\left(1-\hat{\tau}_{l, t}\right)+\left[q_{t}+\left(\hat{r}_{t}-q_{t} \delta\right)\left(1-\hat{\tau}_{k, t}\right)\right] k_{t}+\hat{\pi}_{t}\left(1-\hat{\tau}_{\pi, t}\right)\right)+\hat{p}_{1} b_{1} .
\end{aligned}
$$

So, consumer budget is satisfied.

Finally, we need to show that the government budget constraint is satisfied under newly defined prices and taxes and the original allocation. In the original equilibrium, we have:

$$
\sum_{t=1}^{\infty} p_{t} g_{t}+p_{1} b_{1}=\sum_{t=1}^{\infty} p_{t}\left(w_{t} l_{t} \tau_{l, t}+\left(r_{t}-q_{t} \delta\right) k_{t} \tau_{k, t}+\pi_{t} \tau_{\pi, t}\right)
$$

First, notice that, in every period $t \geq 1$, the product market policy brings the government 
an additional fiscal burden equal to

$$
\hat{T}_{t}-\hat{\tau}_{s, t} y_{t}=-\frac{1}{\varepsilon_{t}} y_{t} .
$$

Therefore, we need to show that

$$
\sum_{t=1}^{\infty} \hat{p}_{t}\left(g_{t}+y_{t} \frac{1}{\varepsilon_{t}}\right)+\hat{p}_{1} b_{1}=\sum_{t=1}^{\infty} p_{t}\left(\hat{w}_{t} l_{t} \hat{\tau}_{l, t}+\left(\hat{r}_{t}-q_{t} \delta\right) k_{t} \hat{\tau}_{k, t}+\hat{\pi}_{t} \hat{\tau}_{\pi, t}\right) .
$$

One can show that, by construction of new taxes and prices

$$
\left(\hat{r}_{t}-q_{t} \delta\right) k_{t} \hat{\tau}_{k, t}-\left(r_{t}-q_{t} \delta\right) k_{t} \tau_{k, t}=\frac{1}{\varepsilon_{t}} F_{k, t} k_{t}
$$

and

$$
\hat{w}_{t} l_{t} \hat{\tau}_{l, t}-w_{t} l_{t} \tau_{l, t}=\frac{1}{\varepsilon_{t}} F_{l, t} l_{t}
$$

Plugging (80) and (81) into (77), and using the fact that $F$ is a constant returns to scale production function, we see immediately that (79) holds with equality. We have shown that the original allocation constitutes an equilibrium with proposed product market policies and under the newly constructed prices and taxes. The fact that the government budget constraint (79) satisfies (19) then follows from the fact that (79) is equivalent to (77), which as Proposition 1 shows, satisfies (19).

\section{A.4 Proof of Proposition 5}

Proof. First, it follows from the first-order optimality condition of the Ramsey problem with respect to consumption, given by (56), that under the preference structure assumed in this proposition, at a steady state, we have

$$
\mu^{*}=u_{c}^{*}\left(1+\lambda^{*}(1-\sigma)\right)
$$


which implies that at a steady state, we have

$$
\chi^{*^{-1}}=\frac{\mu^{*}}{\lambda^{*} u_{c}^{*}}=\lambda^{*^{-1}}+1-\sigma
$$

Second, under the Cobb-Douglas production function, one can show that

$$
\mathcal{E}_{y, 1-\tau_{k}}^{*}<\frac{\alpha}{1-\alpha}
$$

Plugging $S_{\pi}^{-1}=\varepsilon$, and (83) and (84) into the lower bound formula (40) in Corollary 1 proves the proposition.

\section{A.5 Proof of Proposition 6}

Proof. Suppose $S_{\pi, t-1}=S_{\pi, t}=S_{\pi, t+1}=0$ for some $t \geq 3$. That $S_{\pi, t}=0$ implies that the first-order condition for capital given by (54) becomes

$$
\left(k_{t}\right):-\mu_{t-1}^{*} q_{t-1}+\mu_{t}^{*}\left(F_{k, t}^{*}+(1-\delta) q_{t}\right)=0 .
$$

Together with the assumption on preferences, that $S_{\pi, t}=S_{\pi, t+1}=0$ implies that the firstorder optimality condition for consumption for period $t$ given by (56) becomes

$$
\left(c_{t}\right): \beta^{t-1} u_{c, t}^{*}\left[1+\lambda^{*}(1-\sigma)\right]-\mu_{t}^{*}=0
$$

That $S_{\pi, t-1}=S_{\pi, t}=0$ implies that the first-order optimality condition for consumption for period $t-1$ becomes

$$
\left(c_{t-1}\right): \beta^{t-2} u_{c, t-1}^{*}\left[1+\lambda^{*}(1-\sigma)\right]-\mu_{t-1}^{*}=0 .
$$


Combining (85), (86) and (87), we get

$$
u_{c, t-1}^{*} q_{t-1}=\beta u_{c, t}^{*}\left(F_{k, t}^{*}+(1-\delta) q_{t}\right) .
$$

Plugging (88) into (33) gives $\tau_{k, t}^{*}=0$. That $S_{\pi, t}=0$ implies that the first-order condition for labor given by (55) becomes

$$
\left(l_{t}\right): \beta^{t-1} u_{l, t}^{*}+\lambda^{*} \beta^{t-1}\left[u_{l l, t}^{*} l_{t}+u_{l, t}^{*}\right]+\mu_{t}^{*} F_{l, t}^{*}=0 .
$$

Plugging (86) and (89) into (34) gives the result.

\section{A.6 Proof of Proposition 7}

Proof. Letting $\mu_{t}$ and $\lambda$ be LaGrange multipliers on period $t$ feasibility constraint and implementability constraint, the first-order conditions of Ramsey problem (45) for $t \geq 2$ are:

$$
\begin{gathered}
\left(k_{t}\right):-\mu_{t-1}^{*} q_{t-1}+\mu_{t}^{*}\left(\left(1-\frac{1}{\varepsilon_{t}}\right) F_{k, t}^{*}+(1-\delta) q_{t}\right) \\
-\lambda^{*} \beta^{t-1} u_{c, t}^{*}\left[\left(1-\tau_{\pi, t}^{*}\right) \frac{\partial \pi_{t}^{*}}{\partial k_{t}}+\frac{\partial\left(1-\tau_{\pi, t}^{*}\right)}{\partial k_{t}} \pi_{t}^{*}\right]=0, \\
\left(l_{t}\right): \beta^{t-1} u_{l, t}^{*}+\lambda^{*} \beta^{t-1}\left[u_{l l, t}^{*} l_{t}+u_{l, t}^{*}\right] \\
-\lambda^{*} \beta^{t-1} u_{c, t}^{*}\left[\left(1-\tau_{\pi, t}^{*}\right) \frac{\partial \pi_{t}^{*}}{\partial l_{t}}+\frac{\partial\left(1-\tau_{\pi, t}^{*}\right)}{\partial l_{t}} \pi_{t}^{*}\right]+\mu_{t}^{*}\left(1-\frac{1}{\varepsilon_{t}}\right) F_{l, t}^{*}=0, \\
\left(c_{t}\right): \beta^{t-1} u_{c, t}^{*}+\lambda^{*} \beta^{t-1}\left[u_{c c, t}^{*} c_{t}^{*}+u_{c, t}^{*}\right]-\lambda^{*} \beta^{t-1} u_{c, t}^{*}\left(1-\tau_{\pi, t}^{*}\right) \pi_{t}^{*} \\
-\lambda^{*} \beta^{t-1}\left[u_{c, t}^{*} \frac{\partial\left(1-\tau_{\pi, t}^{*}\right)}{\partial c_{t}} \pi_{t}^{*}+u_{c, t+1}^{*} \frac{\partial\left(1-\tau_{\pi, t+1}^{*}\right)}{\partial c_{t}} \pi_{t+1}^{*}\right]-\mu_{t}^{*}=0 .
\end{gathered}
$$


Combining steady-state versions of (90) and (26), and rearranging gives the capital tax formula. Combining steady-state versions of (91) and (27), and rearranging gives the labor tax formula.

\section{A.7 Proof of Proposition 8}

Proof. By taking the terms inside the bracket on the right-hand side of (46) into $\left(1-\tau_{\pi}^{*}\right)$ parenthesis and using $\tau_{\pi}^{*}=\tau_{k}^{*}$, we obtain the following formula for optimal capital income tax rate

$$
\frac{\tau_{k}^{*}}{1-\tau_{k}^{*}}=\frac{F_{k}^{*}}{\left(1-\frac{1}{\varepsilon}\right) F_{k}^{*}-\delta q} \chi^{*} S_{\pi}\left[1+\frac{\mathcal{E}_{1-\tau_{k}, k}^{*}}{\mathcal{E}_{y, k}^{*}}\right],
$$

where $\mathcal{E}_{1-\tau_{k}, k}^{*}=\left.\frac{d \ln \left(1-\tau_{k}\right)}{d k}\right|_{k=k^{*}}$ is the elasticity of the retention rate (one minus the tax rate) on capital income with respect to the equilibrium level of capital stock and $\mathcal{E}_{y, k}^{*}=\left.\frac{d \ln y}{d k}\right|_{k=k^{*}}$ is the elasticity of national income with respect to the capital stock. Then, we use the transformation

$$
\frac{\mathcal{E}_{1-\tau_{k}, k}^{*}}{\mathcal{E}_{y, k}^{*}}=\frac{1}{\mathcal{E}_{k, 1-\tau_{k}}^{*} \mathcal{E}_{y, k}^{*}}=\frac{1}{\mathcal{E}_{y, 1-\tau_{k}}^{*}},
$$

where $\mathcal{E}_{y, 1-\tau_{k}}^{*}$ is the elasticity of national income with respect to the tax rate on capital income. Plugging this back into (93), we obtain

$$
\frac{\tau_{k}^{*}}{1-\tau_{k}^{*}}=\frac{F_{k}^{*}}{\left(1-\frac{1}{\varepsilon}\right) F_{k}^{*}-\delta q} \chi^{*} S_{\pi}\left[1+\frac{1}{\mathcal{E}_{y, 1-\tau_{k}}^{*}}\right]
$$

It follows from the first-order optimality condition of the Ramsey problem with respect to consumption, given by (92), that under the preference structure assumed in this proposition, at a steady state, we have $\mu^{*}=u_{c}^{*}\left(1+\lambda^{*}(1-\sigma)\right)$, which implies that at a steady state, we have

$$
\chi^{*^{-1}}=\frac{\mu^{*}}{\lambda^{*} u_{c}^{*}}=\lambda^{*^{-1}}+1-\sigma .
$$


Under the Cobb-Douglas production function, one can also show that

$$
\mathcal{E}_{y, 1-\tau_{k}}^{*}<\frac{\alpha}{1-\alpha} .
$$

Plugging $S_{\pi}^{-1}=\varepsilon$, and (95) and (96) into equation (93) proves the proposition.

\section{A.8 Proof of Proposition 9}

Proof. Letting $\mu_{t}$ and $\lambda$ be LaGrange multipliers on period $t$ feasibility constraint and im-

plementability constraint, the first-order conditions of Ramsey problem (49) for $t \geq 2$ are:

$$
\begin{gathered}
\left(k_{t}\right):-\mu_{t-1}^{*} q_{t-1}+\mu_{t}^{*}\left(F_{k, t}^{*}+(1-\delta) q_{t}\right)-\lambda^{*} \beta^{t-1} u_{c, t}^{*}\left(1-\bar{\tau}_{\pi, t}\right) \frac{\partial \pi_{t}^{*}}{\partial k_{t}}=0, \\
\left(l_{t}\right): \beta^{t-1} u_{l, t}^{*}+\lambda^{*} \beta^{t-1}\left[u_{l, t}^{*} l_{t}+u_{l, t}^{*}\right]-\lambda^{*} \beta^{t-1} u_{c, t}^{*}\left(1-\bar{\tau}_{\pi, t}\right) \frac{\partial \pi_{t}^{*}}{\partial l_{t}}+\mu_{t}^{*} F_{l, t}^{*}=0, \\
\left(c_{t}\right): \beta^{t-1} u_{c, t}^{*}+\lambda^{*} \beta^{t-1}\left[u_{c c, t}^{*} c_{t}^{*}+u_{c, t}^{*}\right]-\lambda^{*} \beta^{t-1} u_{c c, t}^{*}\left(1-\bar{\tau}_{\pi, t}\right) \pi_{t}^{*}-\mu_{t}^{*}=0 .
\end{gathered}
$$

Combining steady-state versions of (97) and (26), and rearranging gives the capital tax formula. Combining steady-state versions of (98) and (27), and rearranging gives the labor tax formula.

\section{B Alternative Calibration of Exogenous Profit Taxes}

Recall that, in the benchmark calibration of Section 5.2, the profit tax rate $\tau_{\pi}$ decreases from $40 \%$ to $30 \%$ following the observed capital income tax series. As a sensitivity analysis, we also consider an "alternative calibration" in which the time-series for $\tau_{\pi}$ is equalized to the observed tax rate on distributions (see McGrattan and Prescott 2010), decreasing from 
a level of $40 \%$ to $15 \%$ over the period of interest.

Calibration. Figure B.1. shows the $\tau_{\pi}$ time-series used in our benchmark and alternative parameterizations. We recalibrate the model under this time series for profit taxes using the same methodology as in Section 5.2. We also report the $A P K-\tilde{R}$ implication of the alternative calibration and compare it with the one implied by the benchmark calibration. As Table B.1 shows, we find that the alternative calibration leads to a higher increase in $A P K-\tilde{R}(6.5 \%)$ compared to the one in benchmark calibration (5.4\%). In this sense, the alternative calibration provides an $A P K-\tilde{R}$ series that is more in line with the data. This is a direct implication of the fact that lower levels of $\tau_{\pi}$ implies higher levels of $A P K-\tilde{R}$ as observed in equation (44). Now we report optimal tax analysis results for both calibrations.

Profit Tax Series in Benchmark

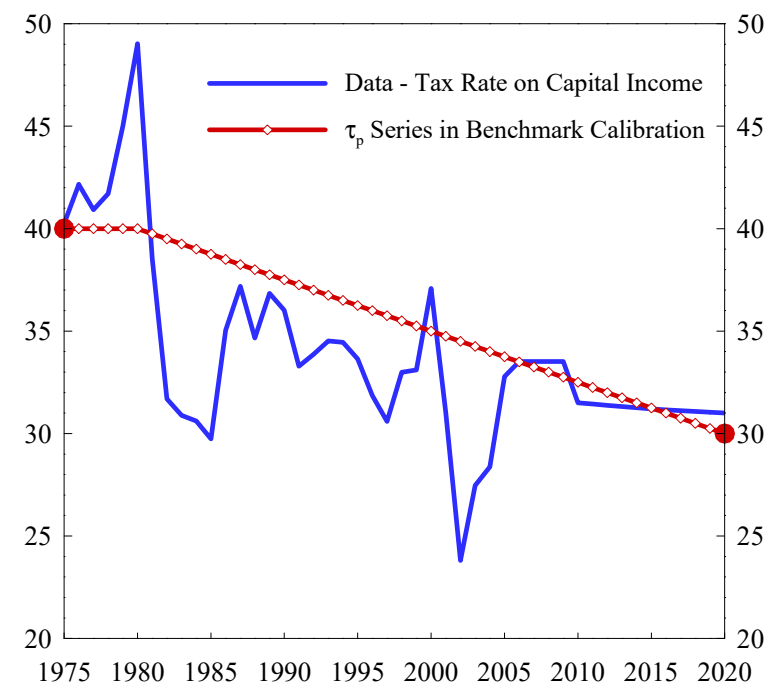

Profit Tax Series in Alternative Calibration

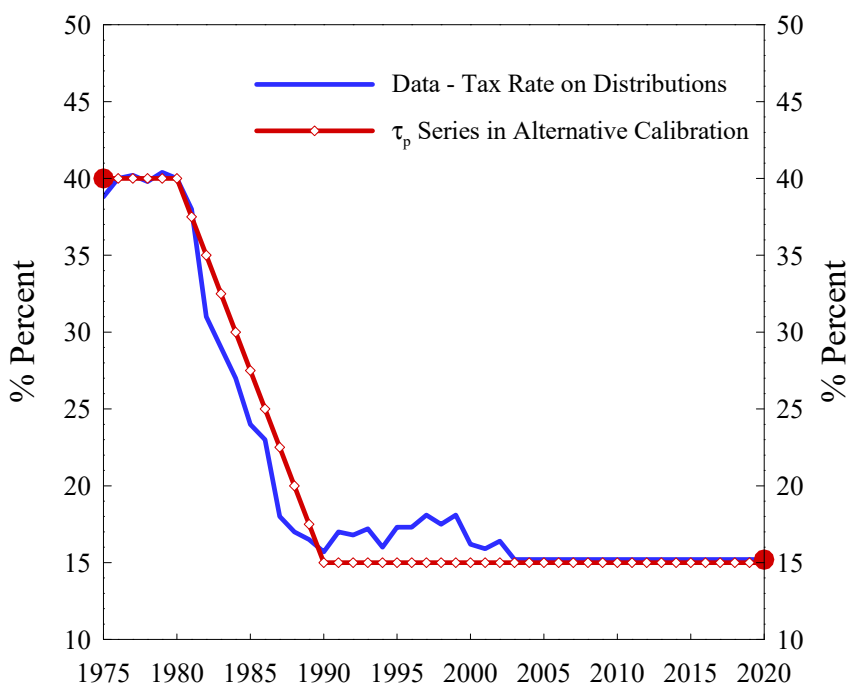

Figure B.1. Profit Tax Series - Benchmark vs. Alternative Calibration

Figure B.2. illustrates the time-path of optimal capital income taxes. Under alternative calibration, we find that optimal capital income taxes are again positive and somewhat higher than the ones implied by the benchmark calibration. We also observe a similar pattern for the optimal labor income taxes under the alternative calibration. To sum up, our quantitative 
Table B.1. APK-r (Data vs. Simulations)

Benchmark vs. Alternative Calibration

\begin{tabular}{lcc}
\hline \hline & 1982 & 2020 \\
\hline \hline Data & $-0.4 \%$ & $7.5 \%$ \\
Benchmark & $0.2 \%$ & $5.4 \%$ \\
Alt. Calibration & $0.2 \%$ & $6.5 \%$ \\
\hline \hline
\end{tabular}

findings verify that, under alternative assumptions on the evolution of actual $\tau_{\pi}$ series, the optimal capital income taxes are still significantly positive in case of exogenous profit taxes.

A. Optimal Capital Income Taxes

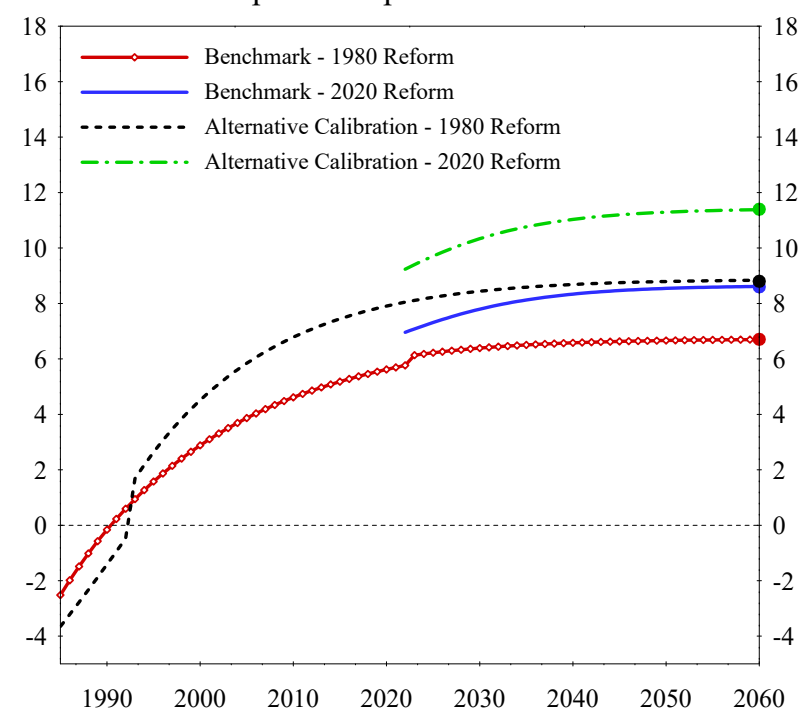

B. Optimal Labor Income Taxes

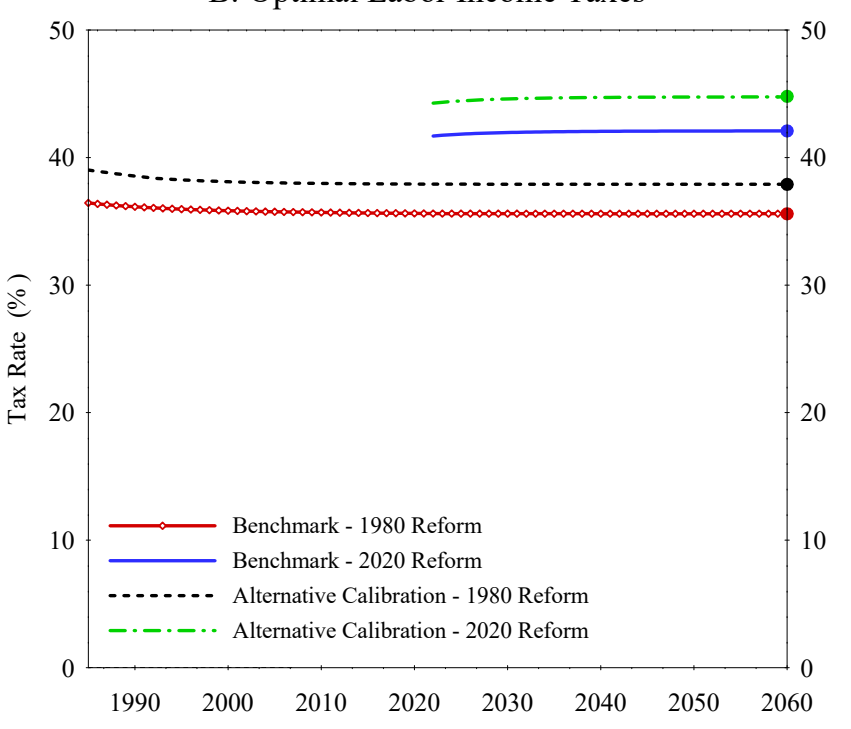

Figure B.2. Optimal Ramsey Taxes : Product Market Interventions $-\tau_{\mathrm{p}}$ fixed 